\title{
A High-Density Narrow-Field Inhibitory Retinal Interneuron with Direct Coupling to Müller Glia
}

\author{
William N. Grimes, ${ }^{1,2 *}$ Didem Göz Aytürk, ${ }^{3 *}$ Mrinalini Hoon, ${ }^{4 *}$ (i) Takeshi Yoshimatsu, ${ }^{4}$ Clare Gamlin, ${ }^{4}$ \\ Daniel Carrera, ${ }^{2}$ Amurta Nath, ${ }^{2}{ }^{-}$Francisco M. Nadal-Nicolás, ${ }^{5}$ Richard M. Ahlquist, ${ }^{1}$ Adit Sabnis, ${ }^{2}$ \\ David M. Berson, ${ }^{6}{ }^{\circledR}$ Jeffrey S. Diamond, ${ }^{2}{ }^{\circledR}$ Rachel O. Wong, ${ }^{4}$ Connie Cepko, ${ }^{3}$ and ${ }^{\circledR}{ }^{\circ}$ Fred Rieke ${ }^{1}$ \\ ${ }^{1}$ Department of Physiology and Biophysics, University of Washington, Seattle, Washington $98195,{ }^{2}$ National Institute of Neurological Disease and \\ Stroke, National Institutes of Health, Bethesda, Maryland 20892, ${ }^{3}$ Harvard Medical School, Blavatnik Institute, Howard Hughes Medical Institute, \\ Boston, Massachusetts 02115, ${ }^{4}$ Department of Biological Structure, University of Washington, Seattle, Washington 98195, ${ }^{5}$ Retinal Neurophysiology \\ Section, National Eye Institute, National Institutes of Health, Bethesda, Maryland 20892, and ${ }^{6}$ Department of Neuroscience, Brown University, \\ Providence, Rhode Island 02912
}

Amacrine cells are interneurons composing the most diverse cell class in the mammalian retina. They help encode visual features, such as edges or directed motion, by mediating excitatory and inhibitory interactions between input (i.e., bipolar) and output (i.e., ganglion) neurons in the inner plexiform layer (IPL). Like other brain regions, the retina also contains glial cells that contribute to neurotransmitter uptake, metabolic regulation, and neurovascular control. Here, we report that, in mouse retina (of either sex), an abundant, though previously unstudied inhibitory amacrine cell is coupled directly to Müller glia. Electron microscopic reconstructions of this amacrine type revealed chemical synapses with known retinal cell types and extensive associations with Müller glia, the processes of which often completely ensheathe the neurites of this amacrine cell. Microinjecting small tracer molecules into the somas of these amacrine cells led to selective labeling of nearby Müller glia, leading us to suggest the name "Müller glia-coupled amacrine cell," or MAC. Our data also indicate that MACs release glycine at conventional chemical synapses, and viral retrograde transsynaptic tracing from the dorsal lateral geniculate nucleus showed selective connections between MACs and a subpopulation of retinal ganglion cell types. Visually evoked responses revealed a strong preference for light increments; these "ON" responses were primarily mediated by excitatory chemical synaptic input and direct electrical coupling with other cells. This initial characterization of the MAC provides the first evidence for neuron-glia coupling in the mammalian retina and identifies the MAC as a potential link between inhibitory processing and glial function.

Key words: amacrine; gap junctions; glia; retina; synapse; vision

Significance Statement

Gap junctions between pairs of neurons or glial cells are commonly found throughout the nervous system and play multiple roles, including electrical coupling and metabolic exchange. In contrast, gap junctions between neurons and glia cells have rarely been reported and are poorly understood. Here we report the first evidence for neuron-glia coupling in the mammalian retina, specifically between an abundant (but previously unstudied) inhibitory interneuron and Müller glia. Moreover, viral tracing, optogenetics, and serial electron microscopy provide new information about the neuron's synaptic partners and physiological responses.

Received Jan. 22, 2020; revised May 16, 2021; accepted May 17, 2021.

Author contributions: W.N.G., D.G.A., M.H., T.Y., C.G., D.C., A.N., F.M.N.-N., A.S., J.S.D., R.O.W., C.C., and F.R. designed research; W.N.G., D.G.A., M.H., T.Y., C.G., D.C., A.N., F.M.N.-N., R.M.A., A.S., and D.M.B. performed research; W.N.G., D.G.A., M.H., T.Y., C.G., D.C., R.M.A., A.S., D.M.B., R.O.W., and C.C. analyzed data; W.N.G., D.G.A., M.H., C.C., and F.R. wrote the first draft of the paper; W.N.G., D.G.A., M.H., T.Y., C.G., D.C., R.M.A., A.S., J.S.D., R.O.W., C.C., and F.R. edited the paper; W.N.G., D.G.A., M.H., T.Y., J.S.D., R.O.W., C.C., and F.R. wrote the paper.

This work was supported by Howard Hughes Medical Institute to C.C., D.G.A., and F.R.; National Eye Institute EY10699 to R.O.W. and EY12793 to D.M.B.; National Institute for Neurological Disorders and Stroke NS083848 to D.G.A. and C.C.; National Institute for Neurological Disorders and Stroke, Intramural Research Program NS003145 to J.S.D.; McPherson Eye Research Institute's Rebecca Meyer Brown/Retina Research Foundation Professorship to M.H.; and Research to Prevent Blindness, Inc. unrestricted grant to University of
Wisconsin Madison Department of Ophthalmology and Visual Sciences to M.H. We thank Shellee Cunningham and Hua Tian for technical assistance; and Passley, Callie, and Leopold Hargrove-Grimes for helpful discussions.

M. Hoon's present address: Department of Ophthalmology and Visual Sciences, University of Wisconsin, Madison, Wisconsin 53705.

C. Gamlin's present address: Allen Institute for Brain Science, Seattle, Washington 98109.

*W.N.G., D.G.A., and M.H. contributed equally to this work.

The authors declare no competing financial interests.

Correspondence should be addressed to William N. Grimes at william.grimes@nih.gov.

https://doi.org/10.1523/JNEUROSCI.0199-20.2021

Copyright $\odot 2021$ the authors 


\section{Introduction}

The circuitry of the mammalian retina uses diverse, parallel circuits to encode many distinct features of the visual world. Amacrine cells, the largest class of inhibitory cell types in the retina, play a critical role in such processing. Amacrine cells are interneurons with cell bodies in either the inner nuclear layer (INL) or ganglion cell layer (GCL), and their processes are typically confined to the most extensive synaptic region of the retina, the inner plexiform layer (IPL; see Fig. 1). They use a diverse array of synaptic mechanisms, including the release of many different neurotransmitters (e.g., GABA, glycine, glutamate, acetylcholine, nitric oxide, dopamine, neuropeptides), as well as gap junctions (i.e., electrical synapses) (for review, see Kolb, 1995; Wu and Maple, 1998; Masland, 2012). Understanding the connectivity and function of amacrine cells is essential to our understanding of how the retina performs computations required for effective and rapid visual processing.

Here, we examine physiological and anatomic characteristics of a previously unstudied high-density, narrow-field amacrine cell. In addition to presenting cell-specific tools (i.e., antibodies and mouse lines), and describing the cell's synaptic connections with other retinal neurons in the IPL (i.e., bipolar, amacrine, and ganglion cells), we provide evidence for previously unknown, direct coupling between this amacrine cell type and Müller glia. Electron microscopic reconstructions of this amacrine revealed that Müller glia extend processes that physically ensheathe this amacrine cell type's neurites in the IPL. Small tracer molecules injected into this amacrine cell diffused into nearby Müller glia, indicating gap junction connections between the two cell types and leading us to suggest the name "Müller glial-coupled amacrine cell" (MAC) for this amacrine cell type. Together, the results presented here suggest that MACs provide local glycinergic inhibition within retinal neural circuits and also mediate interactions with glial cells.

\section{Materials and Methods}

Electrophysiology. Experiments were conducted in accordance with Institutional Animal Care and Use Committee at the University of Washington or in accordance with National Institutes of Health guidelines, as approved by the National Institute of Neurologic Disorder and Stroke Animal Care and Use Committee (ASP 1220). WT and genetically modified (Table 1) C57/Bl6 mice of either sex were dark-adapted overnight before death. Eyes were then immediately enucleated and submerged in warm $\left(\sim 32^{\circ} \mathrm{C}\right)$ bicarbonate-buffered Ames medium (Sigma Millipore) that was continuously bubbled with carbogen $\left(95 \% \mathrm{O}_{2} / 5 \%\right.$ $\mathrm{CO}_{2}$ ). Small scissors were used to remove the cornea. The lens and vitreous were then removed with forceps before storing the retinal cups for up to $6 \mathrm{~h}$ in a customized light-proof storage chamber containing warm oxygenated Ames. To prepare the retina for electrophysiology recordings, we took half an eye cup, isolated the retina from the pigment epithelium, trimmed the retina into a rectangle, and mounted it photoreceptor-side down on a poly-L-lysine-coated microscope slide. A mounted retina was placed in the recording chamber, where it was superfused continuously with $\sim 32^{\circ} \mathrm{C}$ oxygenated Ames. For experiments that probed visual responses, retinal dissections and mounting were conducted exclusively under infrared illumination.

Voltage-clamp whole-cell recordings were conducted with electrodes (retinal ganglion cell [RGC]: 2-3 $\mathrm{M} \Omega$, ACs: 5-6 $\mathrm{M} \Omega$ ) containing the following (in mM): 105 Cs methanesulfonate, 10 TEA-Cl, 20 HEPES, 10 EGTA, 2 QX-314, 5 Mg-ATP, 0.5 Tris-GTP, and 0.1 Alexa (594) hydrazide ( $\sim 280 \mathrm{mOsm}$; $\mathrm{pH} \sim 7.3$ with $\mathrm{CsOH})$. Current-clamp whole-cell recordings were conducted with electrodes (ACs: 5-6 $\mathrm{m} \Omega$ ) containing the following (in mM): $123 \mathrm{~K}$-aspartate, $10 \mathrm{KCl}, 10 \mathrm{HEPES}, 1 \mathrm{MgCl}_{2}, 1$ $\mathrm{CaCl}_{2}$, 2 EGTA, 4 Mg-ATP, 0.5 Tris-GTP, and 0.1 Alexa (594) hydrazide ( $\sim 280$ mOsm; $\mathrm{pH} \sim 7.2$ with $\mathrm{KOH})$. NBQX (10 $\mu$; Tocris Bioscience), APV (25 $\mu \mathrm{M}$; Tocris Bioscience), and MFA (100 $\mu \mathrm{M}$; Sigma Millipore)

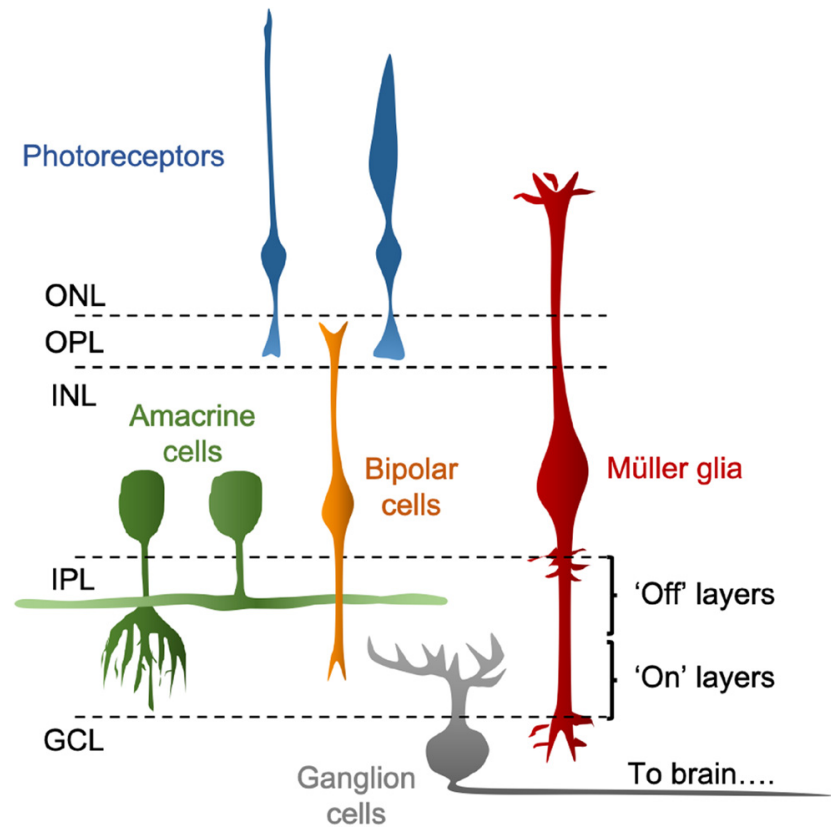

Figure 1. Retinal schematic. Light is captured by rod and cone photoreceptors and converted into neural signals. Light-evoked signals are conveyed from photoreceptors to bipolar cells through glutamatergic synapses in the outer plexiform layer (OPL). Bipolar cells relay signals to amacrine and ganglion cells through glutamatergic synapses in the IPL. Synaptic connections between bipolar, amacrine, and ganglion cells in the IPLs play an important role in feature extraction and the decorrelation of retinal output. Müller glia support retinal function.

were added to the perfusion solution as indicated in Figure 6. APB (10 $\mu \mathrm{M}$; Tocris Bioscience), UBP (25 $\mu \mathrm{M}$; Tocris Bioscience), APV (25 $\mu \mathrm{M})$, and NBQX $(10 \mu \mathrm{M})$ were bath-applied for $>3 \mathrm{~min}$ before testing for ChR2-evoked responses in RGCs. To isolate excitatory or inhibitory synaptic input, cells were held at the estimated reversal potential for inhibitory or excitatory input of $\sim-60$ and $\sim 10 \mathrm{mV}$, respectively. Absolute voltage values were corrected for liquid junction potentials $\left(\mathrm{K}^{+}\right.$-based $=$ $-10.8 \mathrm{mV} ; \mathrm{Cs}^{+}$-based $\left.=-8.5 \mathrm{mV}\right)$.

Full field illumination (diameter: $500-560 \mu \mathrm{m}$ ) was delivered to the preparation through a customized condenser from short wavelength (peak power at 405 or $460 \mathrm{~nm}$ ) LEDs. Light intensities (photons $/ \mu \mathrm{m}^{2} / \mathrm{s}$ ) were converted to photoisomerization rates $\left(\mathrm{R}^{\star} /\right.$ photoreceptor/s) using the estimated collecting area of rods and cones ( 0.37 and $0.5 \mu \mathrm{m}^{2}$, respectively), the LED emission spectra, and the photoreceptor absorption spectra (Govardovskii et al., 2000). Flashes were $10 \mathrm{~ms}$ in duration, except for ChR2 experiments, which used a $50 \mathrm{~ms}$ flash. In Figure $6 A, B$, the video monitor was set to a mean of $\sim 200 \mathrm{R}^{*} / \mathrm{rod} / \mathrm{s}$ and contrast steps were $0.5 \mathrm{~s}$ in duration.

Electrophysiology example traces presented throughout the figures represent the average of 5-20 raw responses to the same stimuli for a single cell. All averaged traces were baseline-corrected before amplitude assessment. For flash responses (from darkness), the mean amplitude was assessed for a $50 \mathrm{~ms}$ time window centered on the peak of the largest control response for a given cell (and held constant for all other conditions). For $0.5 \mathrm{~s}$ steps (increments and decrements) on a $\sim 200 \mathrm{R} * / \mathrm{rod} / \mathrm{s}$ background, mean amplitude was assessed for a $0.5 \mathrm{~s}$ window that was delayed from the onset of the step by $50 \mathrm{~ms}$.

Immunohistochemistry. For immunohistochemical experiments, retinae were isolated in cold oxygenated mouse ACSF, pH 7.4, containing the following (in mM): $119 \mathrm{NaCl}, 2.5 \mathrm{KCl}, 2.5 \mathrm{CaCl}_{2}, 1.3 \mathrm{MgCl}_{2}, 1$ $\mathrm{NaH}_{2} \mathrm{PO}_{4}, 11$ glucose, and 20 HEPES. Retinas were fixed in 4\% PFA in ACSF for $20 \mathrm{~min}$, washed in $0.1 \mathrm{~m} \mathrm{PBS}$, and were either incubated with primary antibodies in blocking solution (5\% donkey serum and $0.5 \%$ Triton in PBS) or were embedded in $4 \%$ agar (low-gelling agarose, Sigma Millipore) and sectioned at $120 \mu \mathrm{m}$ in the vibratome. Retina slices were used for immunolabeling with the glycine antibodies (rabbit and rat, gifts from D. Pow). GFP was amplified with an anti-chicken GFP antibody from Abcam, and retina slices were incubated overnight with 
Table 1. Mouse lines used in the MAC study

\begin{tabular}{llll}
\hline Mouse line & Driver gene & Retinal cells labeled & Source \\
\hline Dact2-eGFP & Dapper Antagonist of Catenin 2 & Subset of MACs & MMRRC (stock \#034338-UCD) \\
Plcxd2-eGFP & Phosphatidylinositol-specific phospholipase & Subset of MACs, other amacrines & MMRRC (stock \#034741-UCD) \\
& C, X domain containing 2 & & \\
NEX-Cre(:Ai9) & Neurogenic differentiation 6 & Subset of MACs, other ACs, horizontal cells & Goebbels et al. (2006) \\
Dact2-Cre(:Ai27) & Dapper Antagonist of Catenin 2 & Subset of MACs, unknown wide-field ACs, unknown RGCs & MMRRC (stock \#036640-UCD) \\
PSD95-creEnabled (mVenus) & Postsynaptic density protein 95 & RGCs, ACs, horizontal cells, OFF bipolar cells & The Jackson Laboratory (stock \#029242) \\
VGlut3-Cre(:Aig) & Vesicular glutamate transporter 3 & RGCs, VGlut3 ${ }^{+}$ACs & Grimes et al. (2011) \\
\hline
\end{tabular}

primary antibodies in blocking solution followed by washes in PBS and a $3 \mathrm{~h}$ incubation with anti-isotypic secondary antibodies (Invitrogen or Jackson ImmunoResearch Laboratories). Labeling of Dact2-GFP or Plcxd2-GFP retinas for GAD67 (mouse monoclonal, Millipore), glycine transporter GlyT1 (goat, Millipore), GlyR $\alpha 1$ (mouse, Synaptic Systems), syntaxin 1 (mouse, Sigma Millipore), Cralbp (mouse, Abcam), and PPP1R17 (rabbit, Sigma Millipore) was performed by incubating whole retinas over 3 nights in primary antibody solution followed by washes in PBS and an overnight incubation with anti-isotypic fluorescently conjugated secondary antibodies.

RGCs were either biolistically labeled using the CMV:tdTomato plasmid as described previously (Morgan et al., 2008) or injected with $4 \%$ Neurobiotin. For tracer injection experiments, 4\% Neurobiotin or $4 \%$ Neurobiotin and 2\% Lucifer yellow (in $200 \mathrm{~mm} \mathrm{KCl}$ ) were injected into GFP-positive amacrine cells or Müller glia endfeet in the Plcxd2-GFP or Plcxd2-GFP:PSD-95-YFP lines. Retinas were subsequently fixed for 20 min in 4\% PFA in ACSF. To amplify the tracers after fixation, streptavidin conjugated to AlexaFluor (Invitrogen) was used for Neurobiotin and an anti-Lucifer yellow antibody (rabbit, Invitrogen) was used for Lucifer yellow. To label postsynaptic glycine receptors, Glycine receptor alpha1specific monoclonal antibody from Synaptic Systems was used and whole-mount labeling was performed according to the procedure described above. To label vesicular glutamate transporter 3 (VGlut3) amacrine cells, we used a VGlut3 antibody from Synaptic Systems (cata$\log \# 135203)$. All images were acquired with an Olympus FV1000 microscope using a $1.35 \mathrm{NA} 60 \times$ oil objective, and the software Amira (Thermo Fisher Scientific) was used for visualization and 3D rendering. To visualize synaptic contacts within RGCs, the RGC processes were first masked in 3D using the Labelfield function in Amira. Thereafter, the presynaptic amacrine GFP signal was multiplied with the RGC cell mask (using the Arithmetic function in Amira) to isolate the points of apposition between the GFP amacrine processes and RGCs. The immunolabeled glycine receptor signal was also multiplied with the RGC 3D mask to isolate the receptor signal exclusively within the RGC processes. Thereafter, the GFP signal apposed to RGC processes and the glycine receptor signal within RGC processes was covisualized in 3D to ascertain synaptic appositions. The masked RGC was divided into soma, ON dendritic and OFF dendritic compartments for ascertaining number of GFP boutons apposed with each RGC compartment and the fraction of GFP contacts apposed to GlyR $\alpha 1$ within the RGC. To visualize potential synaptic contacts of VGluT3 amacrine cells onto the MAC, a similar process as described above was used. The processes of the VGlut3-labeled cells and MAC were masked using the Labelfield function in Amira. These masks were then multiplied to find sites of signal overlap. This overlapped mask was then multiplied by the Psd95 signal to determine the number of VGlut3 synaptic inputs onto MACs (i.e., VGlut3->MAC appositions with PSD95; data not shown).

Near-infrared branding (NIRB) and serial block face scanning electron microscopy (SBFSEM). Mouse retina from Dact2-GFP transgenic line was flat-mounted on a nitrocellulose filter paper and fixed in $4 \%$ glutaraldehyde in $0.1 \mathrm{~m}$ sodium cacodylate buffer, $\mathrm{pH} 7.4$, for $20 \mathrm{~min}$. The tissue was then washed 3 times and coverslipped in $0.1 \mathrm{~m}$ sodium cacodylate buffer for multiphoton imaging. MACs were identified based on their dendrite stratification level. An image stack was taken using a custom-built two-photon microscope with a Ti:sapphire laser (SpectraPhysics) with voxel dimensions of the multiphoton image stack were as follows: $x y, 0.15 \mu \mathrm{m}$; $z$ step, $0.5 \mu \mathrm{m}$. To relocate the MAC using EM, fiduciary marks were burned into the tissue using the NIRB method (Bishop et al., 2011; Della Santina et al., 2016). The laser power was typically set at $100 \mathrm{~mW}$ measured at the light path before the objective lens. Repeated line scans for a total duration of $10 \mathrm{~s}$ at a wavelength of $780 \mathrm{~nm}$ were performed; the laser power was increased by $20 \mathrm{~mW}$ at a time if burning was not apparent from the autofluorescence. A box was branded at two different tissue depths: at the cell soma and at the RGC layer. After NIRB-ing, the retina was unmounted and fixed in $4 \%$ glutaraldehyde overnight, and then processed for SBFSEM. The tissue was washed 3 $\times 5 \mathrm{~min}$ (all washes) in $0.1 \mathrm{M}$ sodium cacodylate buffer and incubated in a solution containing $1.5 \%$ potassium ferrocyanide and $2 \%$ osmium tetroxide $\left(\mathrm{OsO}_{4}\right)$ in $0.1 \mathrm{M}$ cacodylate buffer $(0.66 \%$ lead in $0.03 \mathrm{~m}$ aspartic acid, $\mathrm{pH}$ 5.5) for $1 \mathrm{~h}$. After washing, the tissue was placed in a freshly made thiocarbohydrazide solution $(0.1 \times g$ TCH in $10 \mathrm{ml}$ double-distilled $\mathrm{H}_{2} 0$ heated to $60^{\circ} \mathrm{C}$ for $1 \mathrm{~h}$ ) for $20 \mathrm{~min}$ at room temperature. After another rinse, at room temperature, the tissue was incubated in $2 \%$ $\mathrm{OsO}_{4}$ for $30 \mathrm{~min}$ at room temperature. The samples were rinsed again and stained en bloc in $1 \%$ uranyl acetate overnight at $4^{\circ} \mathrm{C}$, washed and stained with Walton's lead aspartate for $30 \mathrm{~min}$. After a final wash, the retinal pieces were dehydrated in a graded ice-cold alcohol series, and placed in propylene oxide at room temperature for $10 \mathrm{~min}$. Finally, the samples were embedded in Durcupan resin. Semithin sections $(0.5-1 \mu \mathrm{m}$ thick) were cut and stained with toluidine blue, until the fiducial marks (box) in the GCL appeared. The block was then trimmed and mounted in the SBFSEM microscope (GATAN/Zeiss, 3View). Serial sections were cut at $70-80 \mathrm{~nm}$ thickness and imaged at an $x y$ resolution of $6.0-8.0 \mathrm{~nm}$; $3 \times 3$ tiles, each $\sim 40 \mu \mathrm{m} \times 50 \mu \mathrm{m}$ was obtained with an overlap of $\sim 10 \%$. The image stacks were concatenated and aligned using TrackEM (National Institutes of Health). The MAC was traced using the tracing tools in Track EM.

Two additional SBFSEM datasets were used to explore glial ensheathment in more detail. The first block, K0725, covers a volume size of $\sim 50 \times 210 \times 260 \mu \mathrm{m}$, with a voxel size of $13.2 \times 13.2 \times 26 \mathrm{~nm}$ (Ding et al., 2016). This resolution allows for the visualization of vesicles and chemical synapses but does not allow for identification of gap junctions. The second block used, K0731, was of the approximate size $60 \times 80 \times$ $80 \mu \mathrm{m}$ with a similar voxel size to the K0725 block. The preparation of K0731 block was optimized to preserve extracellular space within the retinal tissue, allowing for identification of gap junctions (Pallotto et al., 2015).

Müller glia were identified by dense internal filament structures that are characteristic of Müller glia and are absent from other cell types in the IPL. From Müller glia reconstructions in K0725, neuronal ensheathments were identified and ensheathed cells were reconstructed, leading to the identification of two narrow-field amacrine cells whose morphology and synaptic organization matched that of the MAC. Subsequently, two additional MACs were found by looking for cells with tight association with Muller processes in the central layers of the IPL. Inputs and outputs on these four cells were then counted and categorized. Synaptically connected bipolar cells were matched to a bank of previously reconstructed bipolar cells (same block) to determine type (Ding et al., 2016).

All cells from these two blocks were reconstructed and annotated using the EM analysis software Knossos (https://knossos.app/), and skeleton renderings for figures were created using the visualization software Paraview (Ahrens et al., 2005).

Viral tracing. All animal husbandry and procedures for these experiments were in accordance with the Longwood Medical Area Institutional Animal Care and Use Committee guidelines. Animals were kept and bred in biosafety containment level 1 conditions at all times, except during and after the VSV injections, which took place in biosafety level 2 conditions. 
Neurod6-Cre (NEX-Cre) mice (a generous gift from Klaus Nave from University of Gottingen) were described previously (Goebbels et al., 2006). NEX-Cre mice were maintained on a C57BL/6 background, and crossed to conditional TVA-expressing (cTVA) mice generated either by the Saur laboratory (Seidler et al., 2008) or by the C.C. laboratory (Beier et al., 2013). During initial studies, a conditional tdTomato reporter mouse (The Jackson Laboratory, stock \#007909, commonly known as Ai9) was also bred to the cTVA mice to obtain a Cre-driven tdTomato reporter and TVA receptor expression. Zero viral transmissions were observed from an infected RGC to an amacrine cell that was not tdTomato ${ }^{+}$, confirming our previous findings of the specificity of envATVA transmission (Beier et al., 2013).

As an alternate way to deliver TVA, we used plasmids or AAV viruses that encode Cre-dependent TVA. Plasmids or AAVs were subretinally injected into conditional NEX-Cre mice at $\mathrm{P} 0-1 ; \sim 0.3 \mu \mathrm{l}$ of virus, AAV-flex-Tcb $(2 / 8)\left(10^{13} \mathrm{gc} / \mathrm{ml}\right)$, or $0.3 \mu \mathrm{l}$ of either one of the plasmids, pAAV-flex-TC66t or pAAV-flex-Tcb $(1 \mu \mathrm{g} / \mathrm{ul})$ (Miyamichi et al., 2013) was injected using a pulled angled glass pipette controlled by a Femtojet (Eppendorf) into the right eye. In the case of plasmids, an electric pulse was delivered right after the injections, to electroporate the construct (AAV preparation and electroporation strategies described previously in detail: Matsuda and Cepko, 2007; Xiong et al., 2015). For the final analysis, data derived from the different methodologies used for TVA delivery were combined.

In an effort to increase viral transmission efficiency, 11 of 74 mice injected in the studies were bred to IFN $\alpha \mathrm{R}^{0 / 0}$ mice (032045-JAX; MMRRC) (Drokhlyansky et al., 2017).

VSV construction and production strategies used in this study were previously described (Beier et al., 2013). Briefly, a recombinant VSV with a chimeric glycoprotein $(\mathrm{A} / \mathrm{G})$ that consists of the extracellular and transmembrane domains of EnvA and cytoplasmic domain of rabies virus glycoprotein (RABV-G) was pseudotyped with RABV-G. All experiments were performed using mice of either sex after weaning, typically around 2-3 months of age.

The pseudotyped VSV(A/G)RABV-G was injected unilaterally into the left dorsal lateral geniculate nucleus, using a stereotaxic instrument (Narishige International) and pulled capillary microdispensers (Drummond Scientific). Injection volume was $250-500 \mathrm{nl}$ (at a $100 \mathrm{nl} / \mathrm{min}$ rate, using an UltraMicroPump III (WPI). VSV(A/G)RABV-G had a concentration of 1$2 \times 10^{8} \mathrm{ffu} / \mathrm{ml}$.

Injection coordinates used were: AP -2.5 from bregma, LM 2, DV -2.75 .

After 2-4 d following VSV injections, mice were killed with $\mathrm{CO}_{2}$, and eyes enucleated. Corneas were removed with small scissors, lenses were removed, and retinae were isolated in cold PBS. Freshly dissected retinae were fixed in ice cold $4 \%$ formaldehyde for $30 \mathrm{~min}$ before $3 \times$ wash with PBS. Whole retinal cups were blocked in 5\%-6\% donkey serum in PBS with $0.3 \%$ Triton X-100 (blocking solution) for $1 \mathrm{~h}$. Retinae were switched to the primary antibody in blocking solution (see below for concentrations) and incubated overnight at $4^{\circ} \mathrm{C}$. The following day, retinae were washed $3 \times$ with PBS, switched to secondary antibody in blocking solution for $3 \mathrm{~h}$ at room temperature, and washed again $3 \times$ with PBS (second wash included a DAPI costain). Finally, all retinae were mounted in Fluoromount-G (Southern Biotechnology).

Primary antibodies used in these experiments were as follows: rabbit anti-PPP1R17 (Sigma Millipore, Prestige Antibodies; HPA047819; 1:200) and chick anti-GFP (Abcam; ab13970, 1:200). Secondary antibodies used in these experiments were as follows: donkey anti-goat AlexaFluor-647 (1:250, Jackson ImmunoResearch Laboratories); donkey anti-rabbit AlexaFluor647 (1:250, Jackson ImmunoResearch Laboratories); and donkey anti-chick AlexaFluor-488 (1:250, Jackson ImmunoResearch Laboratories).

Infected cells in retinal whole mounts were then imaged using an inverted Carl Zeiss LSM780 microscope (Carl Zeiss AG) with 405, 488, and $633 \mathrm{~nm}$ lasers and a $40 \times$ oil objective (Plan Apo $40 \times / 1.3$ oil).

We focused on regions with sparse RGCs labeling to isolate and image individual RGCs. A total of 74 NEX-Cre mice carrying cTVA were injected into the LGN to generate the RGC dataset. Imaged RGCs were divided into two groups as either "connected" (with a virally labeled AC within their dendritic arbors) or "unconnected" (with no other virally infected ACs within their dendritic arbors). RGC images were analyzed using Fiji for stratification depth and dendritic arbor area. The following criteria were used to categorize the RGCs: dendritic diameter, depth of arborization in the IPL, and general appearance of dendritic morphology, such as symmetry and density. Several manuscripts on mouse RGC types were cross-referenced for the final morphotype decision (Sun et al., 2002; Volgyi et al., 2009; Jacoby and Schwartz, 2017). The RGCs with overlapping dendritic arbors were not included in the analysis as they could not be judged reliably in terms of their morphologic features. Virally labeled amacrine cells were only identified as potential MACs if (1) their morphology was clearly visible (i.e., narrowfield amacrine cell with only 1-2 neuritic processes connecting the cell body to its arbor in the ON layers for the IPL) and/or (2) if they labeled for PPP1R17.

FISH. Probe generation and FISH protocol were previously described (Shekhar et al., 2016). Briefly, cDNA was derived from 5-week-old C57BL/6J retina (Jackson ImmunResearch Laboratories, 000664) following RNA extraction (RNAqueous Kit, Ambion, AM1912) and reverse transcription with Superscript III (Thermo Fisher Scientific, 18080051). In order to generate the GlyT1 antisense probe, PCR was performed using the following primer sequences: forward, aagggatgttgaatggtgctgt; reverse, gaaattaatacgactcactatagggccagcaagatgagcatgaagaa. Reverse primer starts with a T7 sequence adaptor to allow in vitro transcription (underlined). We synthesized the probe using the DIG RNA Labeling Mix (Roche Diagnostics, 11277073910).

Tissue samples were prepared according to the methods described previously (Shekhar et al., 2016), with minor modifications. FISH was performed on Dact2-GFP retina sections. Retinae were dissected quickly and fixed in 4\% PFA in PBS at room temperature for $25 \mathrm{~min}$ and washed with PBS $(2 \times, 5$ min each). Then, the retinae were passed through a sucrose gradient until they sank in cold $30 \%$ sucrose in PBS. Retinae were transferred to $1: 130 \%$ sucrose:OCT and incubated for $1 \mathrm{~h}$ in a cold room with gentle shaking. Retinae were embedded in the $1: 130 \%$ sucrose:OCT solution for sectioning; 50 - $\mu$ m-thick sections were adhered to Fisher Superfrost Plus microscope slides coated with poly-D-lysine in $1 \times$ borate buffer, washed $2 \times$ with $\mathrm{dd}_{2} \mathrm{O}$, and dried completely. After the sections were air dried, they were treated with Proteinase K $(1.5 \mu \mathrm{g} /$ $\mathrm{ml}$, NEB, P8107S), postfixed in 4\% PFA followed by acetic anhydride treatment. After probe hybridization, the GlyT1 probe was detected using anti-DIG-HRP (1:750) and tyramide amplification (PerkinElmer TSA Cy3). This was followed by the immunohistochemistry protocol to amplify the GFP signal in Dact2-GFP retinas. Chick anti-GFP (Abcam; ab13970, 1:200) and donkey anti-chick AlexaFluor-488 (1:250, Jackson ImmunoResearch Laboratories) were used, as described in Viral tracing. These sections were analyzed as described for glycine labeling experiments described in Immunohistochemistry.

The effects of pharmacological manipulations in our electrophysiology experiments were compared with control responses in the same cells, thus allowing for paired statistical comparisons. Data are presented as mean \pm SEM unless otherwise noted. For statistical comparisons, we first determined whether the distributions were random, had equal (or unequal) variance, and were normally distributed using the Runs, Kolmogorov-Smirnov, and Jarque-Bera, respectively. We then used a Wilcoxon Rank test or a Student's $t$ test (depending on the results of the above-mentioned tests) to determine significance; statistical tests and $p$ values are explicitly stated for each instance in the results.

For assessment of IHC or FISH labeling, we quantified glycine immunoreactivity on retinal slices (taken from the Dact2-GFP and Plcxd2GFP lines) by making $\sim 50$ separate measurements of average pixel intensity (within a $\sim 15 \mu \mathrm{m}^{2} \mathrm{ROI}$ ) from somas in the outer nuclear layer (ONL) and INLs. The ONL does not contain glycinergic cells, and was thus used as a null distribution for determining whether glycine levels in cells from the INL, in particular $\mathrm{GFP}^{+}$cells, were significantly different from zero. The mean of the null/ONL distribution was subtracted from all measurements taken from a given slice. Dact2-GFP slices usually contained only a single MAC, so measurements from multiple slices were combined after null subtraction. We determined the appropriate statistical analysis using the same approach described above for our electrophysiology experiments. GAD67 and GlyT1 antibodies were tested on 
A

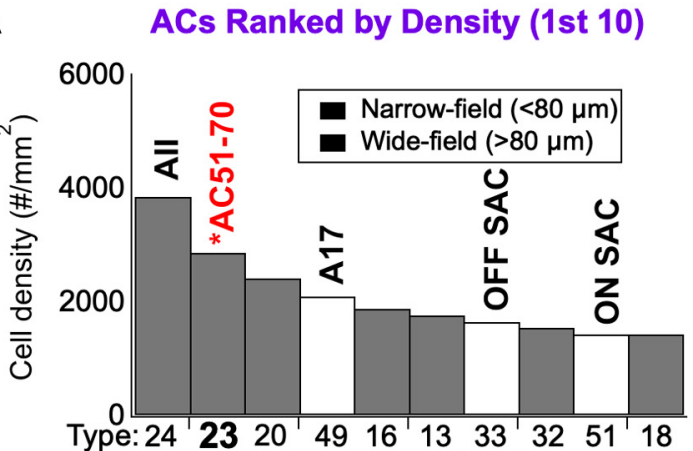

B

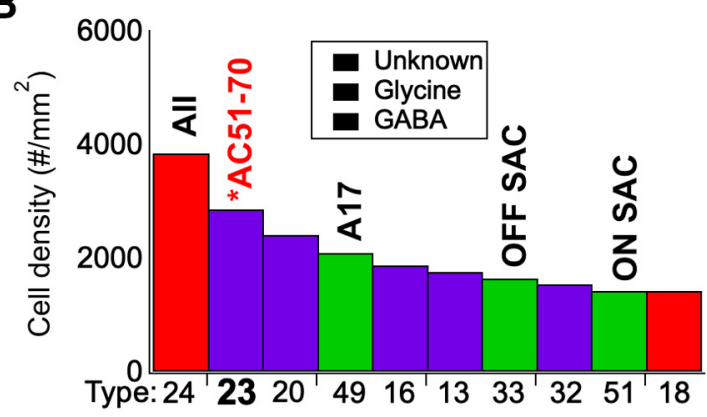

C Type 23/AC51-7.0

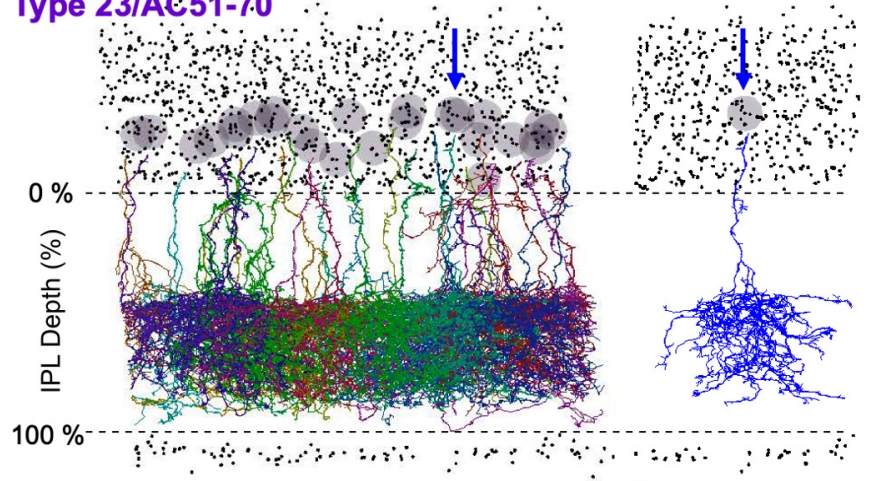

D
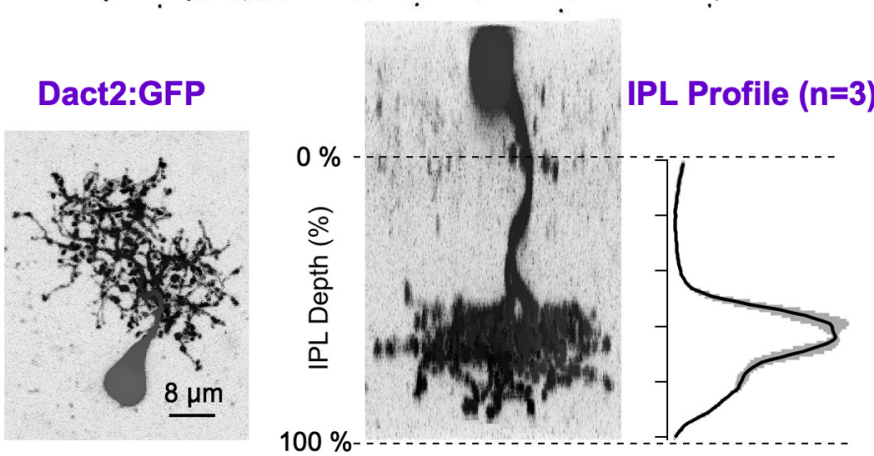

E

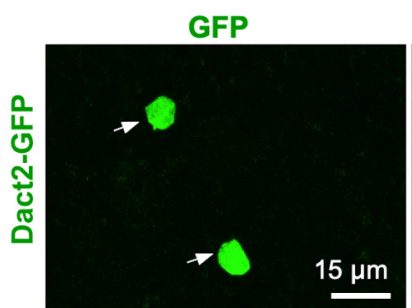

F
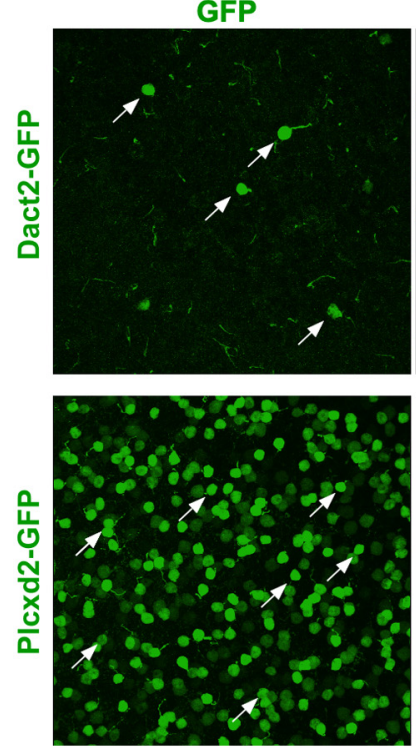

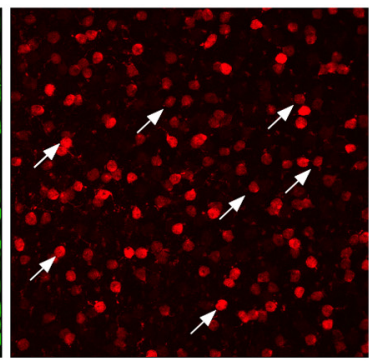

Syntaxin

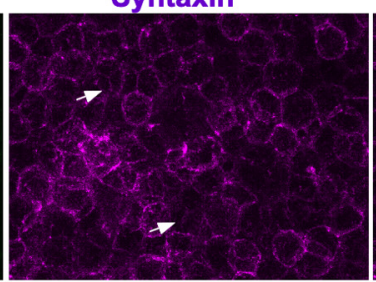

PPP1R17
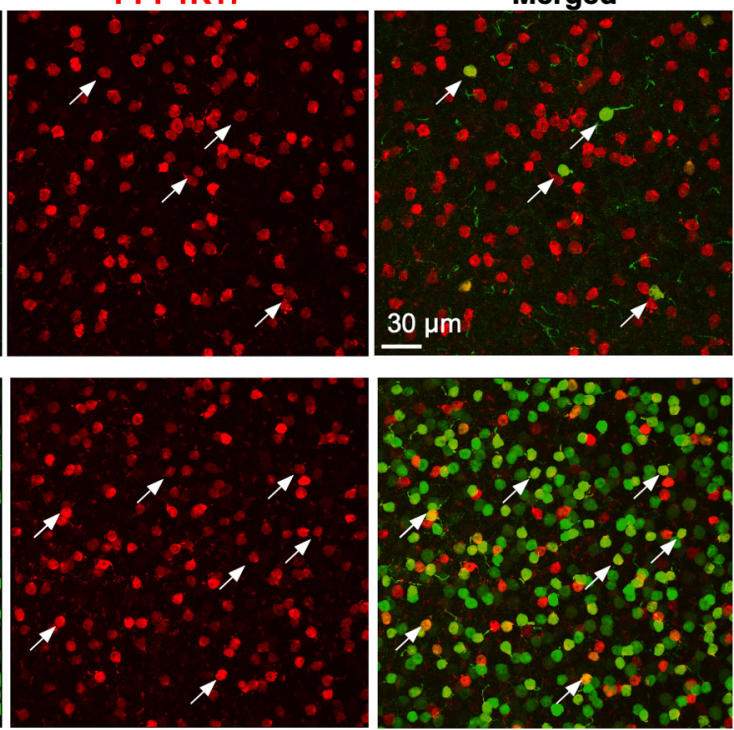

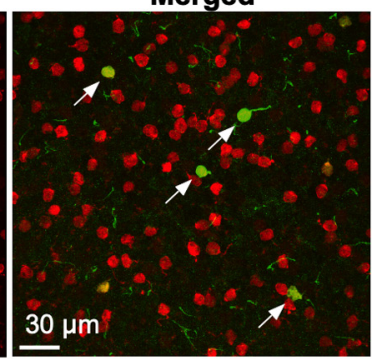

$\mathbf{G}$
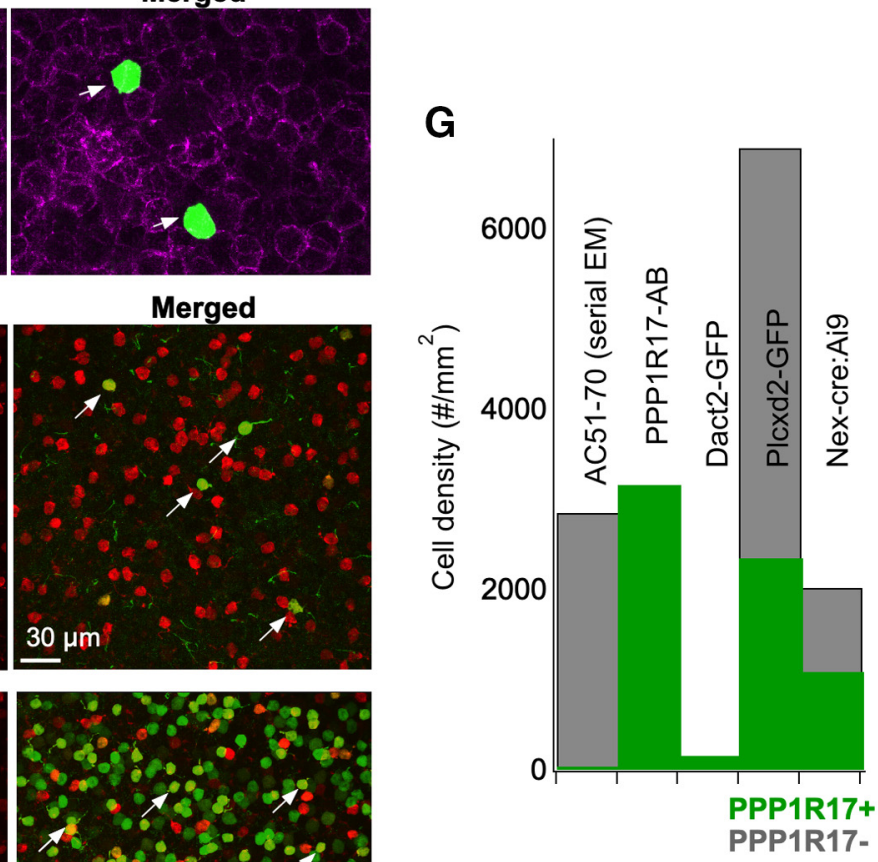

Figure 2. Identification of a high-density, narrow field amacrine cell, the MAC (also known as AC51-70 and Type 23). $\boldsymbol{A}$, The 10 amacrine cell types with the highest spatial density in the mouse retina ranked according to density (Helmstaedter et al., 2013). $\boldsymbol{B}$, The top 10 amacrine cell types (as in $\boldsymbol{A}$ ) color-coded according to what is known regarding their inhibitory neurotransmitters (i.e., GABAergic, glycinergic, unknown). C, Left, Reconstructions of MACs, adapted from Helmstaedter et al. (2013). Right, Example of a single MAC. Blue arrow points to the corresponding cell in the population. D, MACs are uniquely and sparsely labeled in the Dact2-GFP line. Top and side views of an MAC labeled with GFP in the Dact2-GFP mouse line. Three isolated and strongly labeled MACS (from the Dact2-GFP line) were used to assess stratification within the IPL. Thick line indicates the mean. Shaded region represents SEM. $E$, Anti-syntaxin, an antibody specific to amacrine cells, labeled GFP ${ }^{+}$cells in the Dact2-GFP line (7 of 7 Dact2-GFP ${ }^{+}$cells). $\boldsymbol{F}$, G, Anti-PPP1R17 labeled amacrines at a density similar to that of MACs found in serial EM literature; furthermore, all GFP ${ }^{+}$cells in the Dact2-GFP line were PPP1R17 ${ }^{+}$. G, Other mouse lines used in this study, such as Plcxd2-GFP, NEX-Cre-Tdt, and Dact2-cre-Tdt-ChR2, labeled various fractions of the PPP1R17 ${ }^{+}$cells (e.g., MACs). 

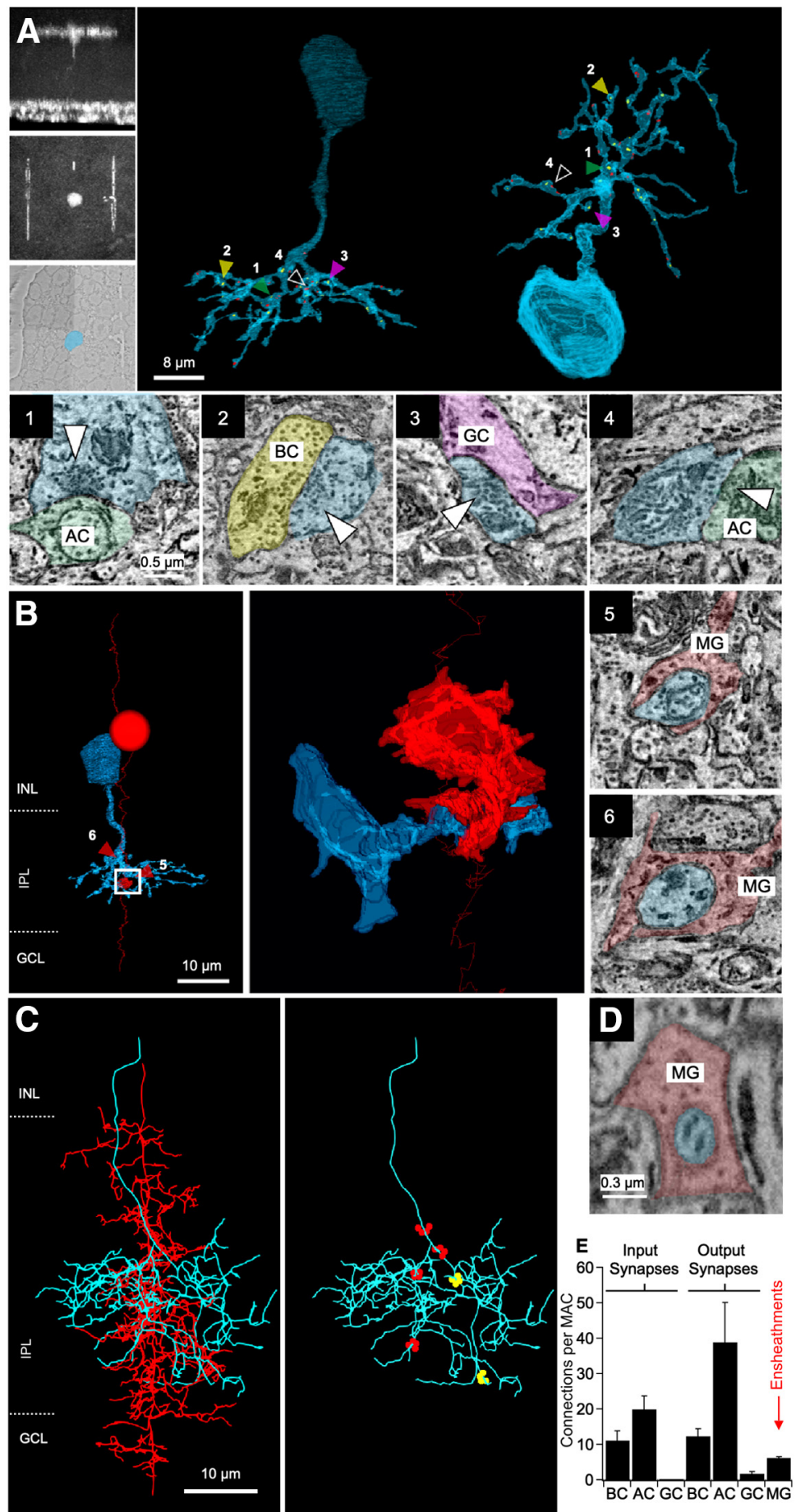

Figure 3. Serial block face EM reconstructions reveal canonical synaptic connectivity and Müller glia (MG) ensheathment. $\boldsymbol{A}$, Left, NIRB marks were used to target a GFP ${ }^{+}$cell in the Dact2-GFP line. Right, The resulting MAC reconstruction revealed conventional output synapses onto amacrine cells (ACs, A1), bipolar cells (BCs, A2), and $\mathrm{RGCS}(\mathrm{GCS}, \boldsymbol{A 3})$, and chemical synaptic inputs from bipolar (shown in Fig. 7) and amacrine cells (A4). $\boldsymbol{B}$, Reconstructions also revealed MG ensheathment (red) of MAC processes (blue, $\boldsymbol{B 5}, \mathbf{B 6}$ ) that lacked obvious chemical synaptic structures. Left, Skeleton and partial reconstruction of MG that ensheathed the identified MAC at multiple locations. Middle, Expanded view of the 3D Müller ensheathment from the white box in the left panel. Right, Electron micrographs of the Müller ensheathments denoted in the left panel with numbers 5 and 6. C, MG reconstructed in another, nonlabeled EM block (K0725) (Graydon et al., 2018) also ensheathed MACs (see Materials and Methods). Left, An example of a MG reconstruction (red) with multiple ensheathments of an amacrine cell (blue) with morphology matching the MAC. Middle, This particular MAC is ensheathed by the red MG at 4 locations within its arbor (red ensheathments), and also with another MG (not shown) at 2 additional locations (yellow ensheathments). The cell bodies for these MG and amacrine cell are missing from this thinner block, which only contains a small fraction of the INL (where their cell bodies typically reside). $\boldsymbol{D}$, Exemplary electron micrograph of an MG ensheathment of an MAC in K0725. $\boldsymbol{E}$, Bar graph summarizes the ultrastructural analysis of 5 reconstructed MACs (mean $\pm \mathrm{SD}$ ). whole-mount retinas, which did not permit the same statistical analysis used on slices for technical reasons (e.g., light scattering and antibody penetration). In these 2 cases, antibody labeling was assessed (yes or no) on a cell-by-cell basis by M.H.

\section{Results}

A recent inventory of the neuronal constituents of the mouse IPL using SBFSEM reconstructions (Helmstaedter et al., 2013) revealed $>45$ morphologically distinct types of amacrine cells. When ranked by density (no. of cell bodies per square millimeter of retina), the majority of the well-studied amacrine cells, including those involved in night vision (AII, A17) and the encoding of directed motion (ON and OFF starburst amacrine cells, or SACs) are among the top 10 (see Fig. 2A). Also, near the top of this list are several amacrine types for which very little is known. More than half of the high-density amacrine types display narrow-field morphologies typically associated with a glycinergic neurotransmitter phenotype (see Fig. 2A,B) (Menger et al., 1998; Pourcho and Goebel, 1983), although this has not been confirmed for all types. We focused on the second most densely distributed amacrine type, initially termed AC51-70 (Helmstaedter et al., 2013), and referred to here as the MAC. These cells are easily recognized by their unique morphology (see Fig. 2C), as they are the only narrow-field amacrine cells that stratify exclusively in the ON layers (inner half) of the IPL (Fig. 1), and have only 1 or 2 processes that connect the synaptic arbor to the soma. Their functional characteristics and circuit wiring, however, remain largely unknown (Pang et al., 2012). Cells with similar morphology have been observed in the primate retina (Polyak, 1941), but as with mouse, we know little about them. Here we combine several techniques to explore the synaptic connectivity and physiology of MACs in the mouse retina.

We identified a mouse line (Dact2-GFP) in the GENSAT (www.gensat.org) database that selectively labels a sparse but homogeneous population of amacrine cells with morphology matching the AC51-70 from Helmstaedter et al. (2013) (Type 23; Fig. 2C, D). Closer inspection of the cells' morphology revealed a monopolar neuron with a small bushy arbor restricted primarily to the inner half of the IPL, and immunohistochemical (IHC) experiments showed that this $\mathrm{GFP}^{+}$cell expresses the amacrine marker, syntaxin (7 of 7 Dact2-GFP $^{+}$cells, $n=3$ animals; Fig. $2 E$ ) (Voinescu et al., 2009). Additionally, we mined the single-cell transcriptomic database for the mouse retina with the purpose of finding markers for the MAC (Macosko et al., 2015). In their initial paper, Macosko et al. (2015) 

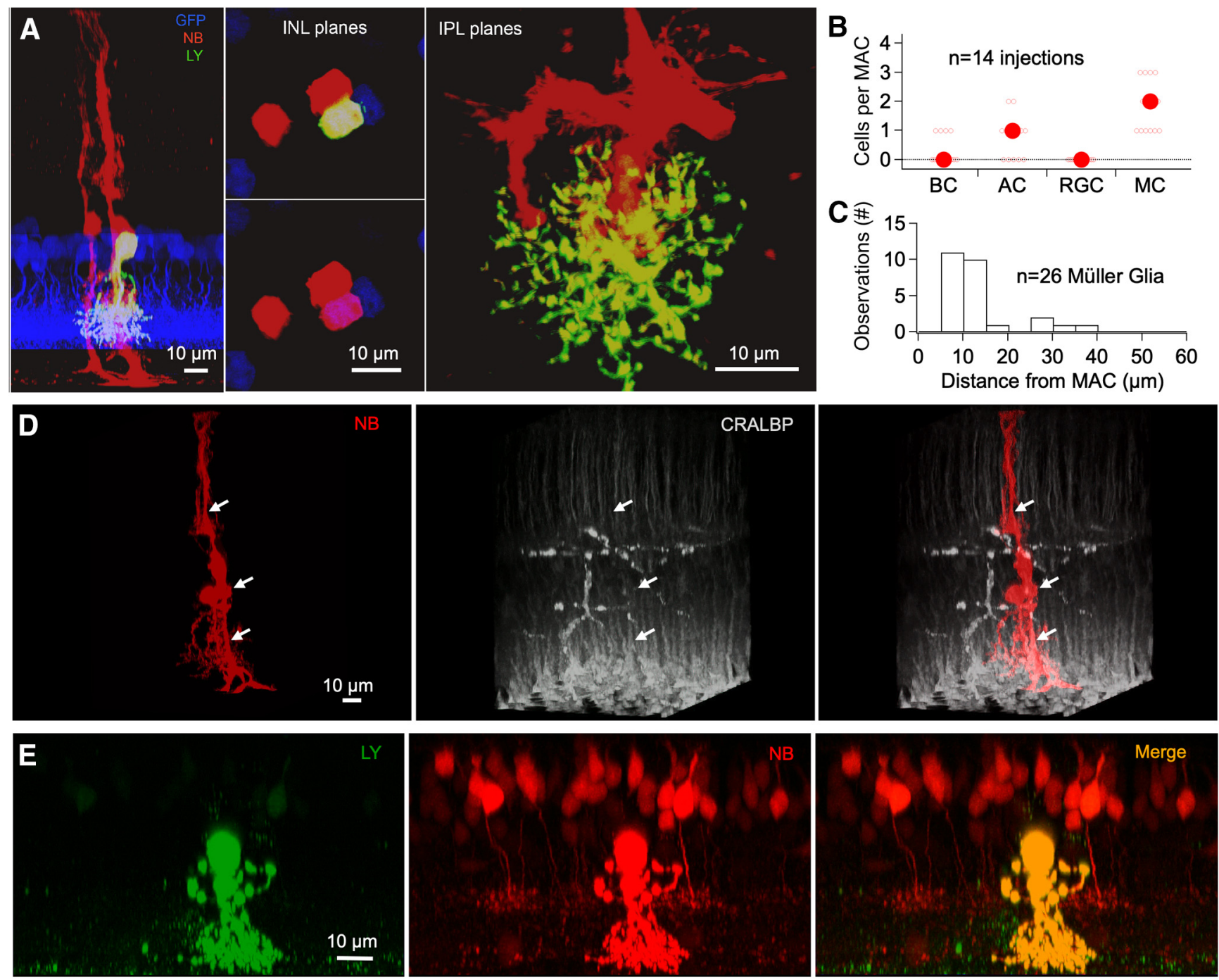

Figure 4. MACs are gap junction-coupled to Müller glia. $A$, A single MAC in the Plcxd2-GFP line was injected with gap junction-permeable (neurobiotin [NB]) and -impermeable (Lucifer yellow $[L Y]$ ) tracer molecules and analyzed using IHC. NB labeled nearby Müller glia, whereas $L Y$ was only observed in the injected MAC, indicating a selective transmission through gap junctions. B,, , Bar graph presentation of the tracer coupling results from 14 single-cell MAC injections. All 14 injections produced NB labeling in at least one Müller glia. $\boldsymbol{B}$, Number of coupled cells per injection broken down by cell type. Large markers represent the median. Small markers represent the results from individual injections. $C$, Histogram represents the intersoma distances of the coupled Müller glia relative to the injected MACS. D, Immunohistochemistry assessment with CRALBP, a label for Müller glia, confirmed that the NB-coupled cells are indeed Müller glia. $\boldsymbol{E}$, A single All amacrine cell injected and analyzed using the same tracer coupling method. Other neurons were labeled by NB in these experiments, but Müller glia cells were not.

identified a cluster (\#20) that strongly expressed mRNA for the protein phosphatase regulatory subunit, PPP1R17. A follow-up study determined that an antibody to PPP1R17 labels several types of narrow-field amacrine cells whose neurotransmitter and physiology were unknown (Yan et al., 2020). We found that this antibody labeled $100 \%$ of the $\mathrm{GFP}^{+}$cells in the Dact2-GFP line (Fig. 2F,G), suggesting that it effectively labels MACs. Furthermore, antiPPP1R17 labeled cell bodies were observed at a similar density to that reported for AC51-70 in Helmstaedter et al. (2013) (Fig. 2G), suggesting that this antibody might label a large population of AC51-70s. We later use this antibody to identify MACs in the absence of a genetically encoded fluorescent label.

\section{MACs make connections with neurons and Müller glia}

We targeted a $\mathrm{GFP}^{+}$cell (i.e., MAC) in the Dact2-GFP line for ultrastructural analysis by performing SBFSEM on tissue in which an MAC had been identified and fiducially marked by NIRB (see Materials and Methods) (Bishop et al., 2011; Della Santina et al., 2016). Partial reconstruction of this MAC revealed a total of 26 synaptic inputs and 20 synaptic outputs, as indicated by clusters of vesicles adjacent to electron-dense regions of membrane (Fig. $3 A$ ). In addition to conventional synapses, the reconstruction also revealed that MAC processes were frequently ensheathed by Müller glial processes (ensheathment defined here as a Müller process surrounding $>50 \%$ of the circumference of a neuronal process) which lacked obvious synaptic structures (Fig. $3 B$ ). These glial ensheathments were found on the descending neuritic stalk and branches of the small bushy arbor of the MAC. Glial ensheathment was not simply a consequence of overlapping processes between high-density cell types, because glial ensheathment was rarely observed in complete reconstructions of two AII amacrine cells, the most numerous amacrine cell type (data not shown). To examine more closely the extent to which glial ensheathment is a true feature of MACs, we reconstructed Müller glia in a larger, previously obtained block-face dataset (K0725) (Graydon et al., 2018) that did not have genetic labels or NIRB. Each reconstructed Müller glia $(n=3)$ in this dataset exhibited multiple neuronal ensheathments throughout the IPL; 

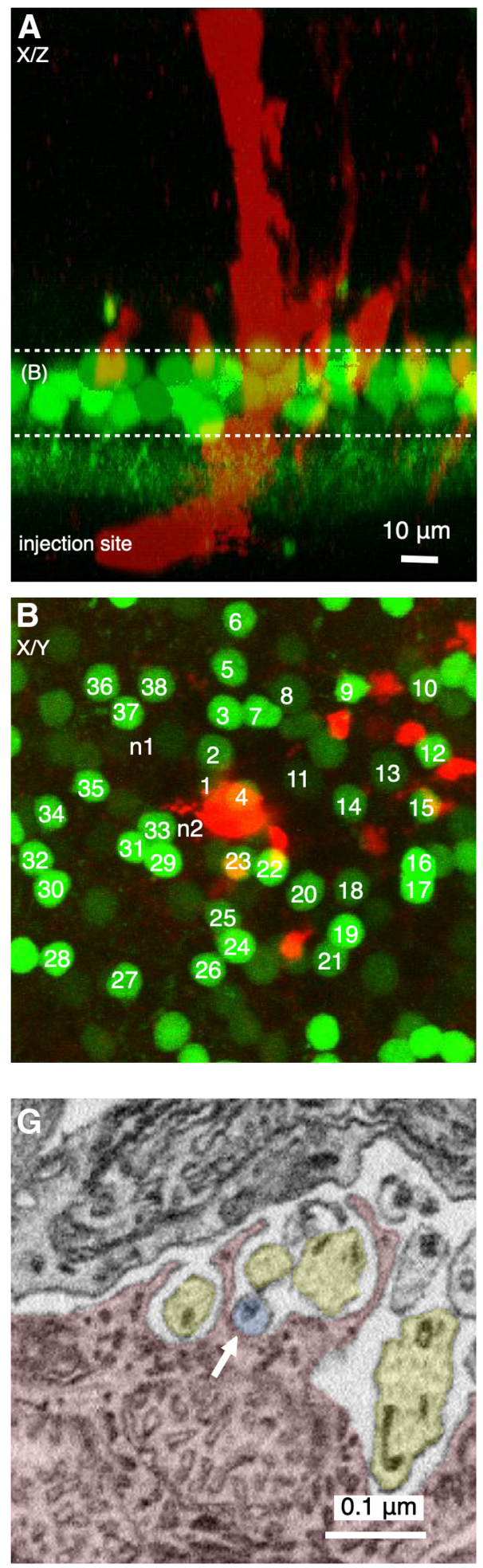

\section{Single Image Planes}

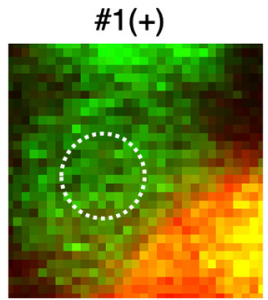

$\# 4(+)$

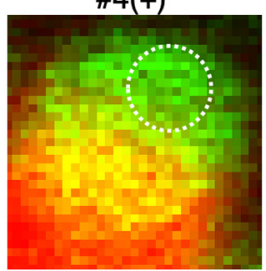

$\# 9(+)$

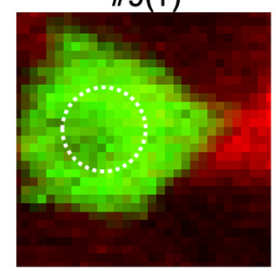

\#23(+)
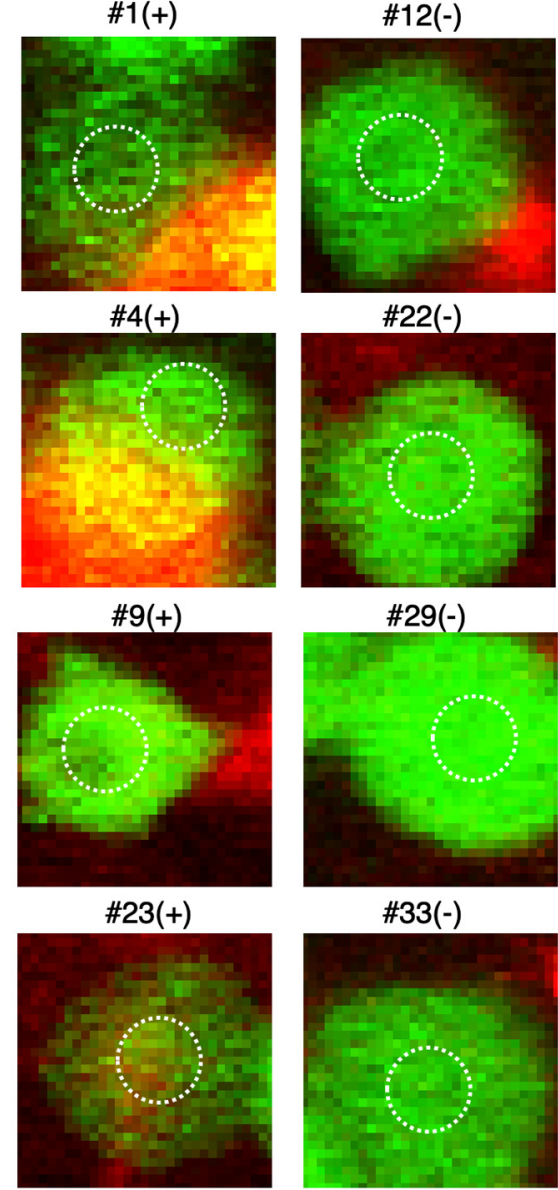

\#22(-)

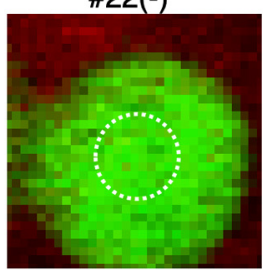

\#29(-)

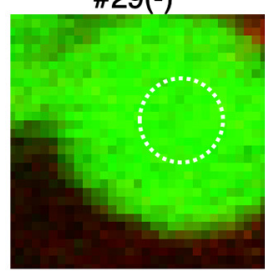

\#33(-)
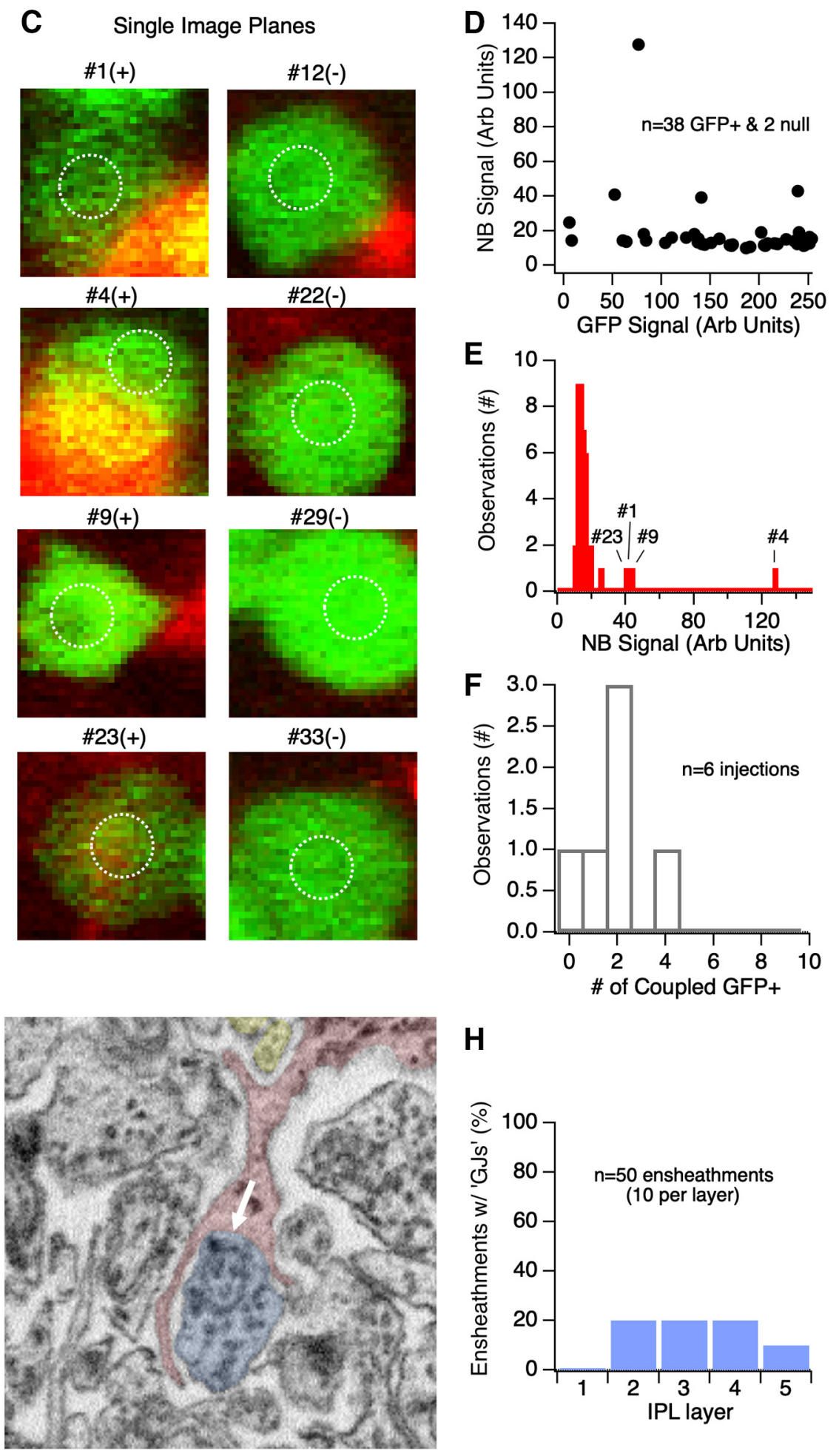

H

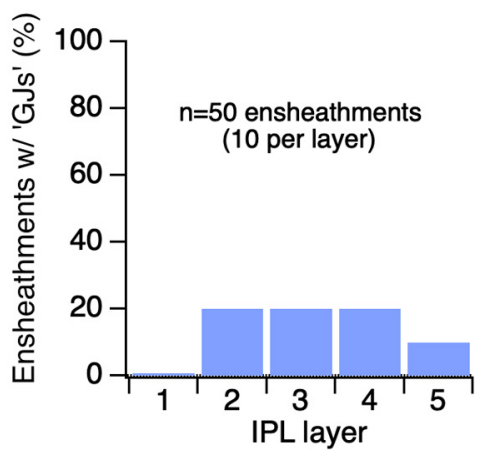

Figure 5. Weak coupling between Müller glia and GFP ${ }^{+}$neurons in the Plcxd2-GFP line. A, Side view of a Müller glia loaded with neurobiotin through the end feed (GCL) in the Plcxd2-GFP line. $\boldsymbol{B}$, Maximum projection of the INL from the stack shown in $\boldsymbol{A}$. Neurobiotin signal was quantified in the somas of the GFP ${ }^{+}$cells surrounding the injected Müller and at two null locations without $\mathrm{GFP}^{+}$(n1 and n2). C, To minimize contamination from signals originating outside the GFP ${ }^{+}$cells, average neurobiotin signal intensity measurements were taken from each GFP ${ }^{+}$ soma ( $\mathrm{ROI}=14 \mu \mathrm{m}^{2}$ circle) in the single-image plane with the largest somatic diameter. Examples of $4 \mathrm{GFP}^{+}$cells with significant levels of neurobiotin coupling (left column) and 4 GFP without significant neurobiotin signal (right column). D, Scatter plot represents the relationship between neurobiotin and GFP signals for $38 \mathrm{GFP}^{+}$cells and 2 null locations. E, Histogram represents the distribution of average neurobiotin signal for the $40 \mathrm{ROI}$ measurements. Positive examples from $\boldsymbol{C}$ are labeled numerically. $\boldsymbol{F}$, Histogram represents the number of tracer-coupled $\mathrm{GFP}^{+}$cells from 6 separate Müller injections. G, Electron micrographs of contact (putative "gap junction," arrow) (Pallotto et al., 2015) between Müller glia (red) and amacrine cells (blue) in the IPL. Yellow shading represents ensheathed neurons without obvious gap junction connectivity. $\boldsymbol{H}$, Potential gap junctions were quantified by examining 10 ensheathments in each of the 5 sublamina (20\% increments; 50 ensheathments in total) for contact between Müller glia ensheathments and neuronal processes. Bar graph represents the percentage of ensheathments containing a presumed gap junction. 
A

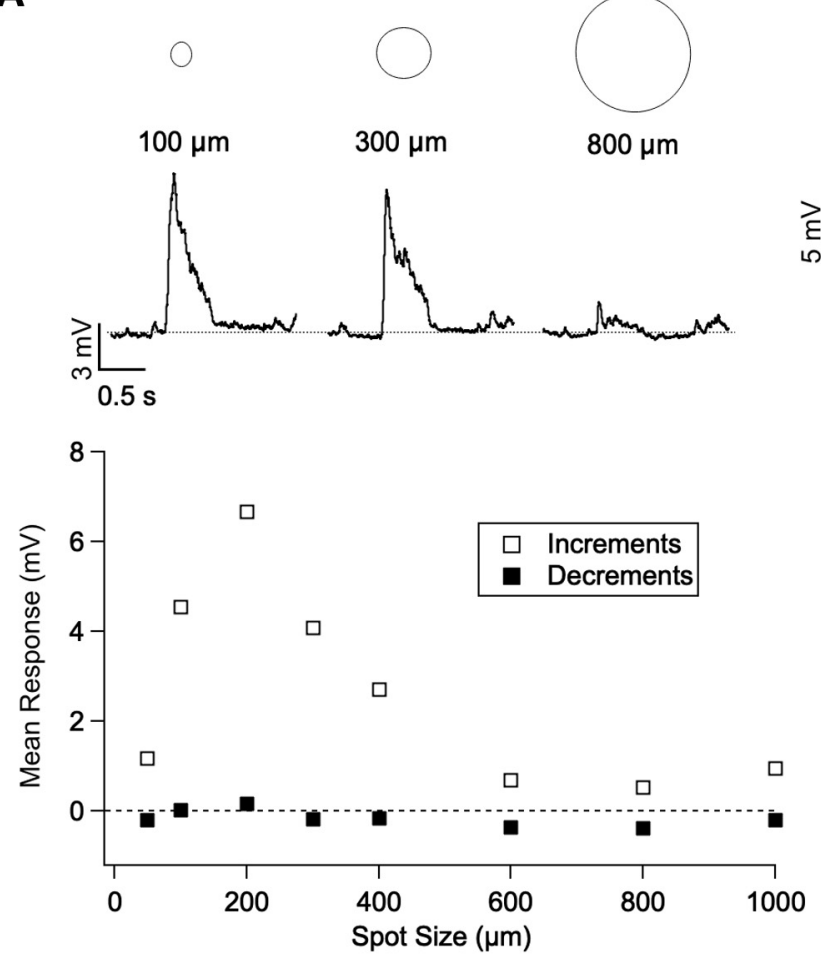

D

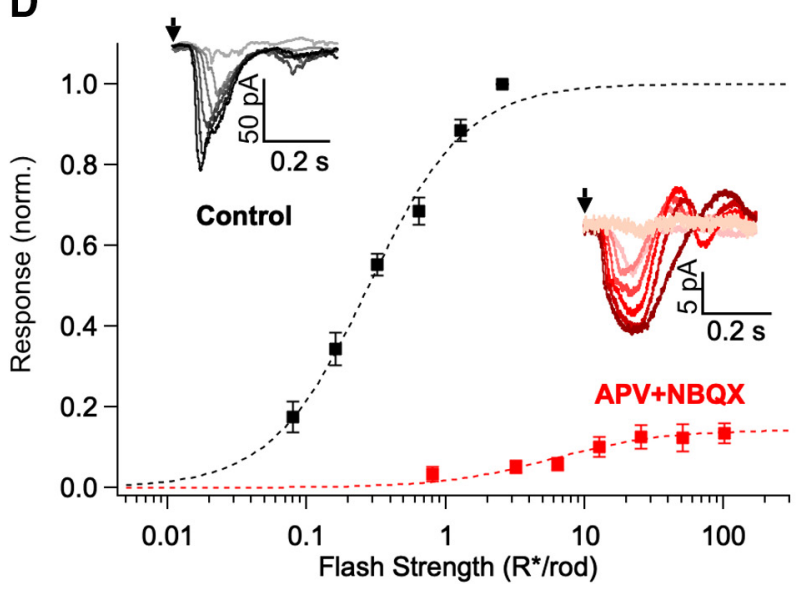

B
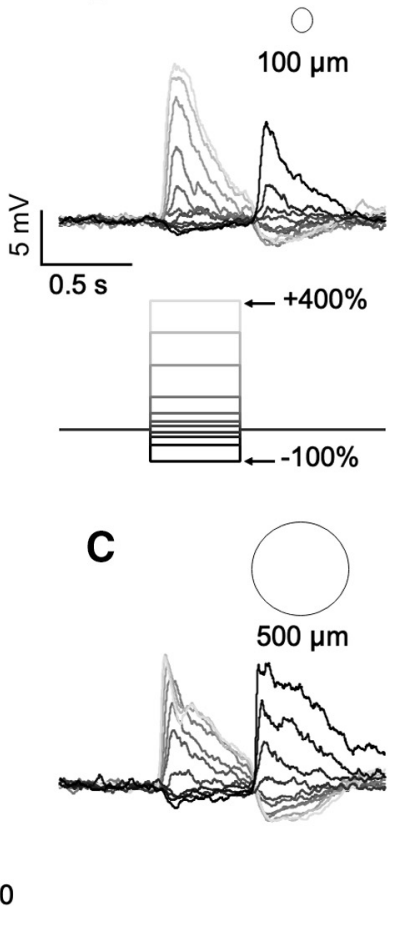
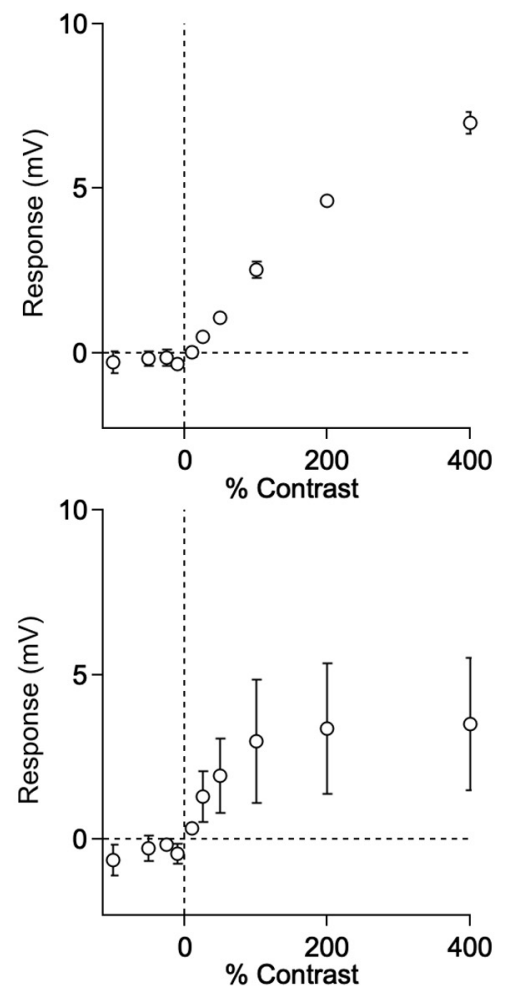

E

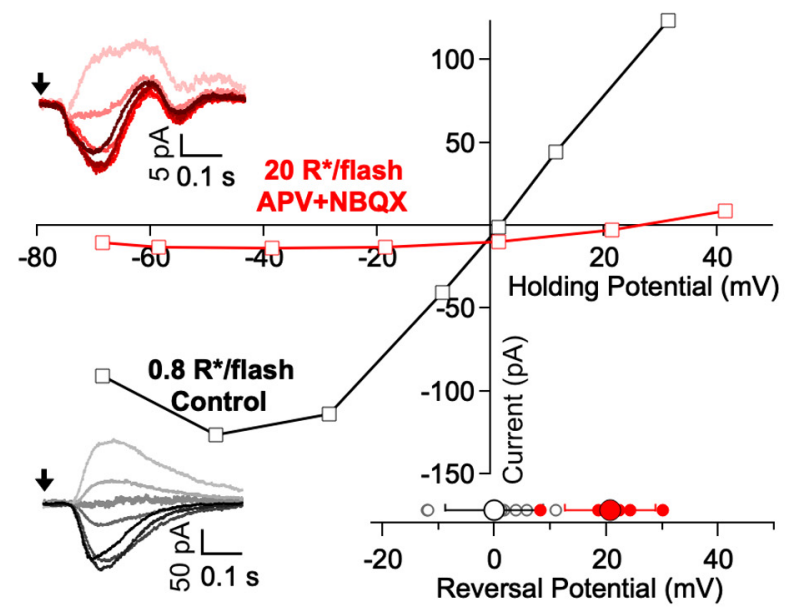

Figure 6. Visually evoked signals and origins of excitatory synaptic input to the MAC. A, Top, Current-clamp recording of visual responses to flashed spots (light increments) of increasing size. Bottom, Response amplitudes plotted as a function of spot size for the example cell. Open markers represent responses to light increments. Closed markers represent responses to light decrements. $\boldsymbol{B}$, Responses to a $100 \mu \mathrm{m}$ spot of various contrasts $(n=4)$. C, Responses to a $500 \mu \mathrm{m}$ spot of various contrasts $(n=4)$. $\boldsymbol{D}$, Voltage-clamp recordings (Vhold $\sim$ reversal potential for chloride) assessing flash sensitivity from darkness. Normalized (to the brightest flash in control) response amplitudes are plotted as a function of flash strength. After control recordings, APV and NBQX were bath-applied to block NMDA and AMPA receptors, respectively. Responses to flashes $\leq 1 \mathrm{R} * / \mathrm{rod} /$ flash were blocked by the cocktail, but further increasing the flash strength under these conditions revealed cocktail-insensitive responses. $\boldsymbol{E}$, Dim flash responses in darkness reversed at the theoretical reversal potential for excitatory glutamate receptors $(\sim 0 \mathrm{mV})$. APV- and NBQX-insensitive light responses emerged as flash strength was increased, and reversed at positive potentials indicating a lack of voltage clamp.

by reconstructing some of the ensheathed neurons $(\sim 30)$, we found two amacrine cells that mirrored the morphology and synaptic organization of the MAC identified using the NIRB technique (Fig. 3C). These putative MACs (including 2 others; see Materials and Methods) were ensheathed by additional Müller glia, with each MAC consistently exhibiting a total of 6 or 7 ensheathments, which in each case could be traced back to a total of 2 Müller glia $(n=4$; Fig. $3 D, E)$. These data indicate that Müller ensheathment is a feature of MACs, and suggest that neurons other than MACs are also ensheathed by Müller glia.

We hypothesized that these ensheathments might enable interactions between neuronal and glia networks, and that gap junctions, which are not easily resolved in conventional SBFSEM reconstructions (Pallotto et al., 2015), may play a role. To test for gap junctions between MACs and Müller glia, we injected gap junction-permeable (neurobiotin) and -impermeable (Lucifer yellow) tracer molecules into MACs (under light-adapted conditions) and analyzed the diffusion of these tracers into coupled cells using IHC (see Materials and Methods) (Mills and Massey, 1995; Vaney et al., 1998; Pang et al., 2010, 2013). These experiments were conducted on another transgenic mouse line (Plcxd2-GFP; Fig. 2F) that labels a larger number of MACs than the Dact2-GFP line (for more information on overlap between PPP1R17 labeling and fluorescent protein expression in the 

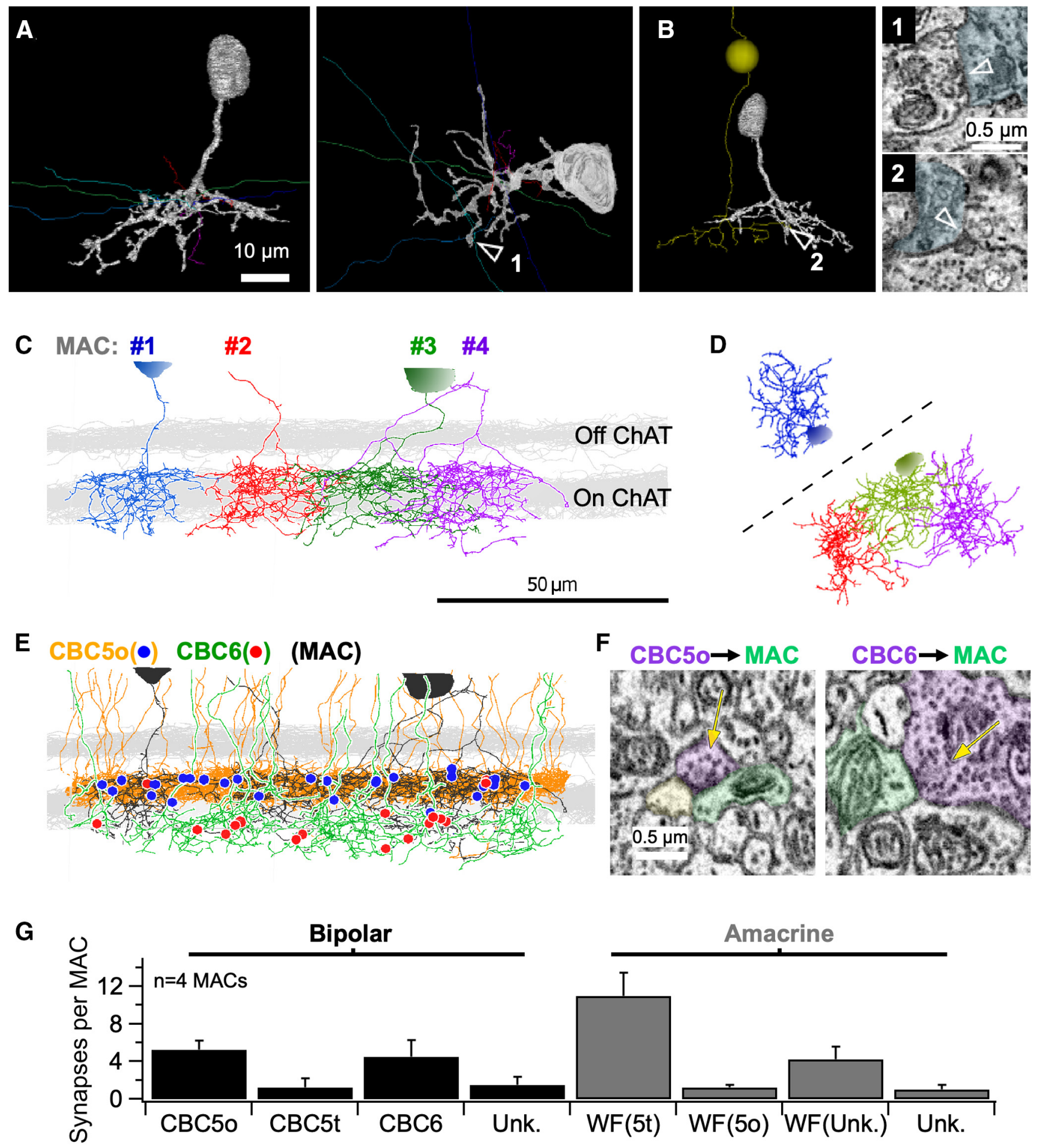

Figure 7. Synaptic input to the MAC from bipolar and amacrine cells. Cells providing synaptic input to MACs were reconstructed in our serial EM blocks. $A$, Side view (left) and top view (right) of the reconstructions of presumed wide-field amacrine processes directly presynaptic to the MAC. B, Side view of a CBC that makes two ribbon-type synaptic contacts with the reconstructed MAC. $\boldsymbol{A}$, EM image of a conventional input synapse denoted by the arrow in $\boldsymbol{A}$. $\boldsymbol{B}$, EM image of a ribbon input synapse denoted by the arrow in $\boldsymbol{B}$. $\boldsymbol{C}$, Side view of 4 skeletonized MACs found in K0725. D, En face view of the MAC synaptic arbors. $E$, MACs receive ribbon input primarily from CBC50 and CBC6 cells. MAC-contacting CBC50's are labeled in orange (blue dots represent synapse locations), and (BC6's are labeled in green (red dots represent synapse locations). $\boldsymbol{F}$, Left, Electron micrograph showing a dyadic ribbon synapse between and (BC50 (purple) and an MAC (green, other dyadic partner in yellow). Right, Electron micrograph showing a CBC6 (purple) making a ribbon synapse onto an MAC (green). G, Bar graph showing the distribution of synaptic inputs to MACs from specific bipolar and amacrine types. Cell types providing $<1$ synapse per MAC, or showing inconsistent connectivity (i.e., found in only 2 or less of the 4 reconstructed MACs) are excluded from this graph but are included in Figure $3 E$.

various mouse lines used in this study, see Fig. 2G). These experiments consistently (14 of 14 injections) produced neurobiotin labeling in Müller glia (Müllers labeled per injected MAC: median $=2$, range $=2-4$; Fig. $4 A, B$ ) surrounding the injected
MAC (MAC-Müller intersomal distance: $13.9 \pm 1.6 \mu \mathrm{m}, n=26$; Fig. $4 C$ ), but not in neighboring MACs (Fig. $4 A$ ). In contrast, Lucifer yellow labeling (included in a subset of injections; $n=4$ ) was constrained to the injected MAC (Fig. 4A). To further 
A
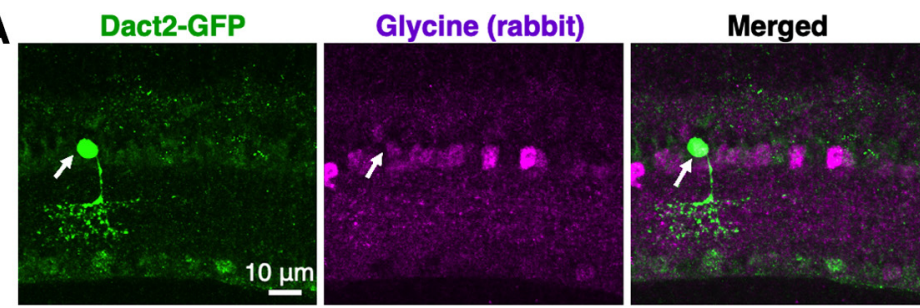

B cell \#1
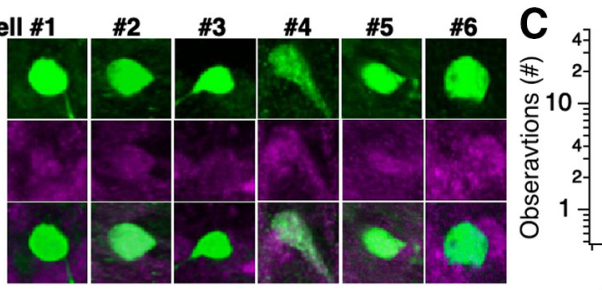

\section{D}
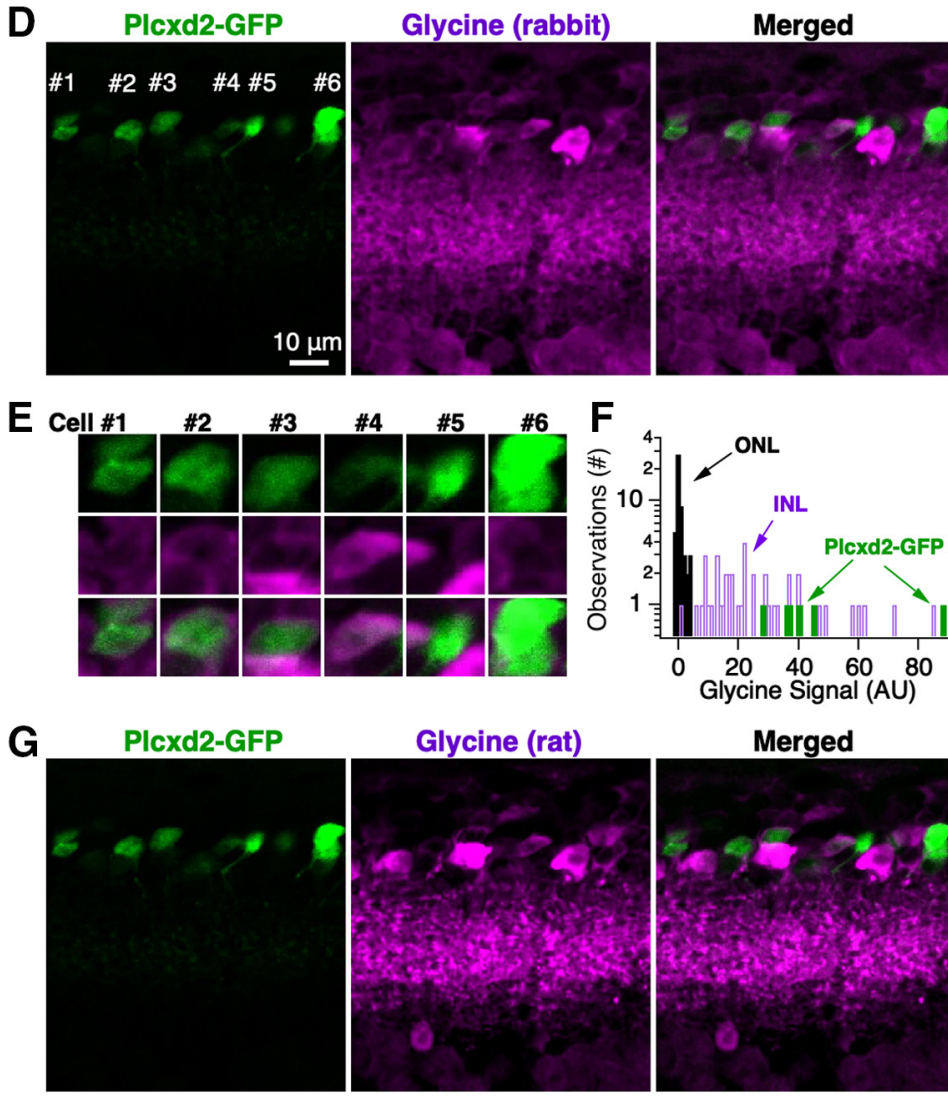

Glycine (rat)
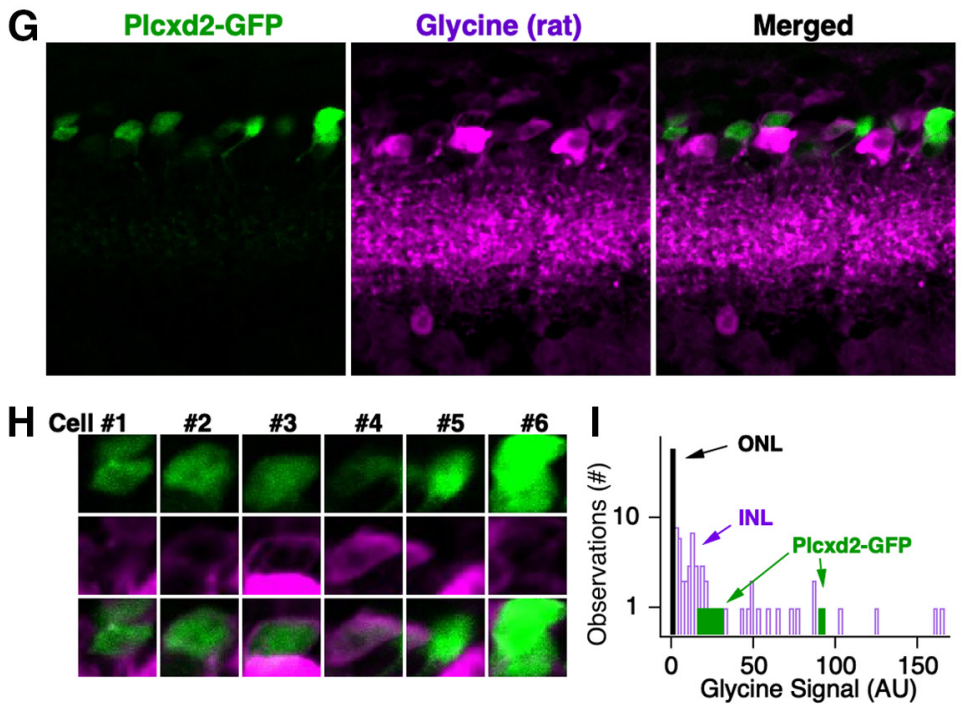

Figure 8. Immunolabeling of Dact2-GFP and PIcxd2-GFP retinas indicates that MACs are glycinergic. $\boldsymbol{A}$, Sections of the Dact2-GFP retina labeled with a rabbit glycine antibody. Left, A GFP ${ }^{+} M A C$. Middle, Staining results from the rabbit glycine antibody. Right, Merged image. B, Higher-magnification views of glycine expression in 6 Dact2-GFP ${ }^{+}$cells. C, Histogram showing the distribution of glycine labeling in the ONL (i.e., a somatic layer devoid of glycine, black) and the INLs (purple) for the example slice in $\boldsymbol{A}$ (Cell \#1). Data from the GFP ${ }^{+}$soma are highlighted in green. $\boldsymbol{D}-\mathbf{I}$, Double labeling of Plcxd2-GFP retina with rabbit and rat glycine antibodies. D, Sections of the Plcxd2-GFP retina labeled with a rabbit glycine antibody. Left, GFP signal. Middle, Staining results from the rabbit glycine antibody. Right, Merged image. $\boldsymbol{E}$, Higher-magnification views of glycine labeling of the $6 \mathrm{GFP}^{+}$cells shown in $\boldsymbol{D}$. $\boldsymbol{F}$, Histogram showing the distribution of glycine signal in the $0 \mathrm{NL}$, INL, and GFP ${ }^{+}$somas of the section shown in $\boldsymbol{D}$. G, Sections of the Plcxd2-GFP retina labeled with a rat glycine antibody. confirm the identity of putative Müller glia, we also used IHC for CRALBP, a known marker for Müller glia (BuntMilam and Saari, 1983). Indeed, suspected Müller glia were immunoreactive for CRALBP (Fig. 4D). This experimental approach occasionally showed additional tracer-coupling to cone bipolar cells (CBCs) and wide-field amacrine cell processes, but these coupling patterns tended to be variable across samples and thus were not pursued further (Fig. 4B). The observed coupling with Müller glia was not a feature common across amacrine cell types, as similar injections into AII amacrine cells $(n=2)$ labeled ON CBCs and a few AII amacrine cells but did not label Müller glia (Fig. 4E) (see also Mills and Massey, 1995; Trexler et al., 2001).

If MACs are coupled to Müller glia via gap junctions, then tracer molecules should, in theory, transmit bidirectionally. However, this notion is likely complicated by the widely different resting membrane potentials of Müller glia $(\sim-80 \mathrm{mV})$ and neurons ( -40 mV) (Jorstad et al., 2017). When applied to a static conductance (e.g., a gap junction), this difference in membrane potential should preferentially drive cations (e.g., neurobiotin, $\mathrm{Na}^{+}, \mathrm{K}^{+}$) from neurons into Müllers and anions (e.g., $\mathrm{Cl}^{-}$, glycine) from glial cells into neurons. With this potential source of rectification in mind, we tested for tracer coupling from Müller glia to MACs in the Plcxd2-GFP line. For these experiments, we patched the endfeet of Müller glia (in the GCL) with a neurobiotin-filled electrode (Fig. $5 A$ ) and used $5 \times$ to $10 \times 0.5 \mathrm{~s}$ current injections of $1 \mathrm{nA}$ to facilitate neurobiotin transfer from Müllers to MACs. Tracer coupling was assessed by measuring the average neurobiotin signal $\left(14 \mu^{2}\right.$ ROI) within individual $\mathrm{GFP}^{+}$somas from single image planes (see Materials and Methods; Fig. 5C-E). Although the strength of neurobiotin coupling was modest compared with MAC injections (Fig. $4 A$ ), we found significant neurobiotin signals in Plcxd2$\mathrm{GFP}^{+}$somas in 5 of 6 Müller glia injections (Fig. 5F). Together, these results indicate that MACs and Müller glia are directly coupled to one another, likely through gap junctions.

Left, GFP signal. Middle, Staining results from the rat glycine antibody. Right, Merged image. $\boldsymbol{H}$, Higher-magnification views of glycine labeling of the $6 \mathrm{GFP}^{+}$cells shown in $\mathbf{G}$. I, Histogram showing the distribution of glycine signal in the ONL, INL, and GFP ${ }^{+}$somas of the section shown in $\mathbf{G}$. 

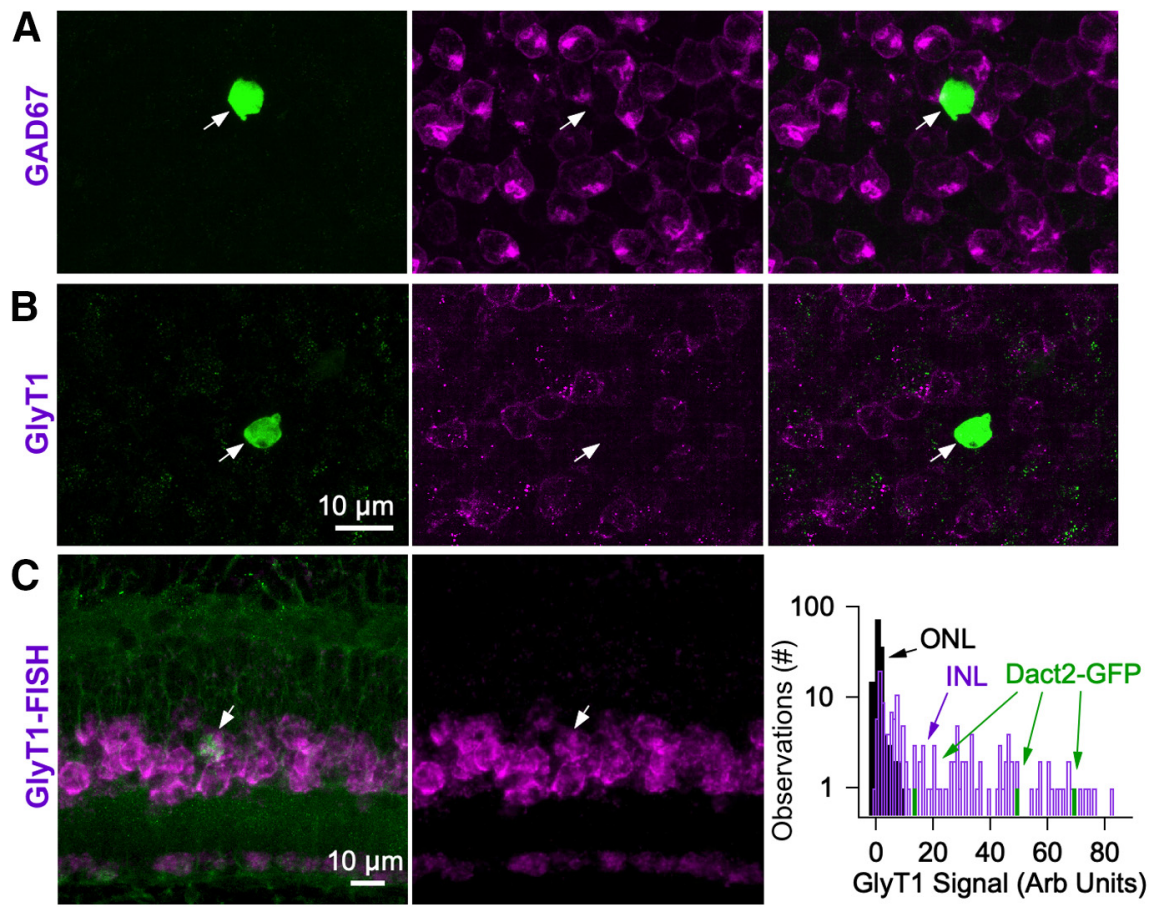

Figure 9. Conventional markers for glycinergic (GlyT1) and GABAergic (GAD67) amacrine cells fail to label MACs in standard immunohistochemistry assays, but FISH reveals low levels of GlyT1 transcript. $\boldsymbol{A}$, An antibody against GAD67 failed to label MACs in the Dact2-GFP line (0 of 18 Dact2-GFP ${ }^{+}$cells). $\boldsymbol{B}$, Dact2-GFP ${ }^{+}$cells were also negative for GlyT1 (0 of 8 Dact2-GFP cells) using traditional IHC methods. C, Low levels of GlyT1 transcript were detected in MACs. A FISH probe was used against GlyT1 in Dact2-GFP retina sections. Left, MAC cell body (green) merged with the GlyT1 signal (magenta). Middle, GlyT1 signal alone. Right, Histograms showing analysis of GlyT1 labeling in ONL, IPL, and Dact2-GFP ${ }^{+}$cells.

Depending on retinal fixation conditions, gap junctions can be observed in electron micrographs as plaques or other electron-rich structures at adjoining membranes (Tsukamoto and Omi, 2017; Sigulinsky et al., 2020). Unfortunately, these structures were not apparent in our NIRBed block (Fig. $3 A$ ), nor the publicly available K0725 block (Fig. 3C) (Ding et al., 2016), even at contacts between cells known to be coupled by gap junctions (e.g., AII-AII, AII-ON CBC) (Graydon et al., 2018). In an effort to determine whether gap junctions are located within glial ensheathments, we turned to another published SBFSEM dataset where gap junctions are identifiable because of preservation of the extracellular space (Pallotto et al., 2015). Under normal conditions, nearly 20\% of the brain's volume consists of extracellular space, which creates a separation between the membranes of neighboring cells, except when a synapse (chemical or electrical) is present. Typical EM fixation protocols use hypo-osmotic solutions that lead to a collapse of extracellular space, which can leave gap junctions, which are not typically surrounded by clusters of intracellular vesicles, difficult to resolve. Although we were unable to find a complete MAC in this much smaller block (see Materials and Methods), partial reconstruction of a Müller glia cell revealed numerous neuronal ensheathments in the IPL. Müller ensheathments (Fig. 5G, red) occasionally contained continuous appositions with amacrine cells (blue) that, in the absence of synaptic vesicles in these fixation conditions, indicates putative gap junctions (Pallotto et al., 2015). Other ensheathed neurons in the IPL (e.g., bipolar and ganglion cells) (Fig. 5G, yellow) did not form continuous contacts with the Müller glia. We quantified the percentage of ensheathments that contained putative neuronal gap junctions by examining 10 examples of neuronal ensheathment within each of the 5 sublayers for continuous membrane apposition (Fig. $5 \mathrm{H}$ ). These data indicate that only a fraction of a Müller glia's neuronal ensheathments contain putative gap junctions (7 of 50 sampled ensheathments, primarily in the central layers of the IPL), and that these connections seem to be made preferentially with amacrine cells.

\section{MAC light responses are primarily driven by on excitatory synaptic inputs}

The light response properties of MACs were investigated by targeting $\mathrm{GFP}^{+}$ cells for whole-cell recordings using two-photon microscopy (980 $\mathrm{nm}$ excitation laser) in dark-adapted Plcxd2-GFP retinas. We began by probing the receptive fields of MACs with brief presentations $(0.5 \mathrm{~s})$ of spots of various sizes (50$1000 \mu \mathrm{m})$ and contrasts $( \pm 100 \%$ on a $200 \mathrm{R}^{*} / \mathrm{rod} / \mathrm{s}$ background). Currentclamp recordings revealed a clear center-surround receptive field (Fig. 6A). We also probed the contrast response function ( $-100 \%$ to $400 \%)$ of MACs for two different spot sizes (diameters: 100 and $500 \mu \mathrm{m})$. MACs exhibited a strong preference for positive contrasts (i.e., light increments) regardless of spot size or stimulus strength (Fig. $6 A-C$ ), consistent with their stratification within the ON layer of the IPL (Fig. 2D).

We next explored the synaptic mechanisms mediating flash sensitivity from darkness using voltage-clamp recordings. At a holding potential of $\sim-68 \mathrm{mV}$, MACs were sensitive to dim flashes $(10 \mathrm{~ms}, 500$ $\mu \mathrm{m}$ spot) that elicited $\sim 0.1$ photoisomerizations per rod per flash $\left(\mathrm{R}^{\star} / \mathrm{rod} /\right.$ flash); saturating responses were elicited by flashes $>1 \mathrm{R}^{\star} / \mathrm{rod} /$ flash (Fig. $6 D$ ). Flash strength was then held constant while varying the holding potential. Flash-evoked signals reversed near $0 \mathrm{mV}(-0.05 \pm 3.3 \mathrm{mV}, n=7$; Fig. $6 E, G)$, the reversal potential for EPSCs mediated by AMPA and/or NMDA receptors, indicating that MACs receive primarily excitatory synaptic input under these conditions. The current-voltage relationship for the EPSCs exhibited outward rectification (Fig. 6G), a characteristic of responses mediated at least in part by NMDA receptors (Dingledine et al., 1999; Manookin et al., 2010). EPSCs evoked by flashes producing $1 \mathrm{R}^{\star} /$ rod or less were almost entirely abolished by a combination of NMDA and AMPA receptor antagonists (to $3 \pm 2 \%$ of control, $n=9, p=4 \times 10^{-5}$, paired Student's $t$ test; Fig. $6 D$ ). However, subsequent increases in flash strength recruited an additional response component with a shallower current-voltage relationship that reversed at significantly larger holding potentials $(20.7 \pm 3.6 \mathrm{mV}, n=5, p=0.002$, paired Student's $t$ test; Fig. $6 E$ ). A weakly voltage-dependent conductance with a positive reversal potential is consistent with gapjunction-mediated input from a retinal cell type with a higher visual threshold (Trexler et al., 2005; Murphy and Rieke, 2011; Grimes et al., 2014; Ke et al., 2014). Accordingly, subsequent application of the gap junction blocker, MFA $(100 \mu \mathrm{M})$, reduced the remaining amplitudes by $61 \pm 14 \%$ within $10 \mathrm{~min}(n=5$, $p=0.006$, paired Student's $t$ test; data not shown). Light-evoked signals transmitted through gap junctions to MACs could come 
A
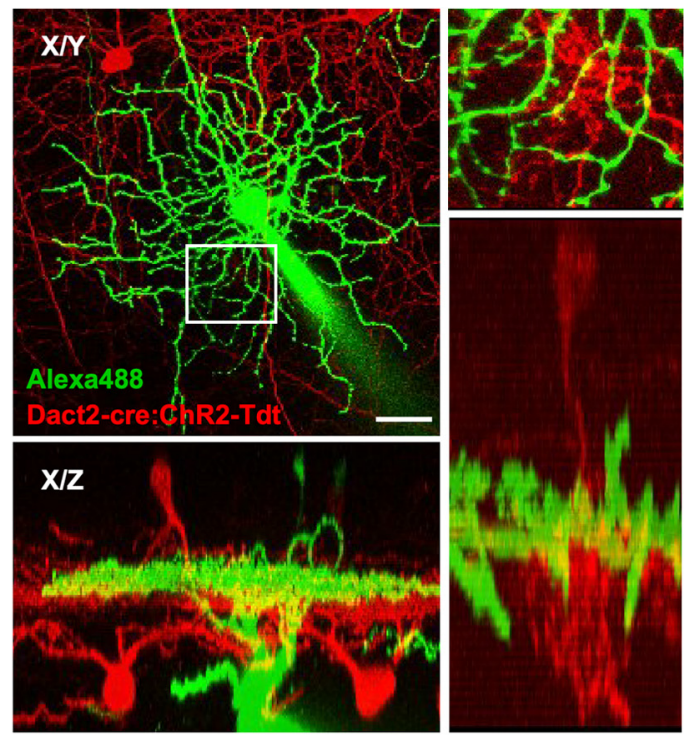

C
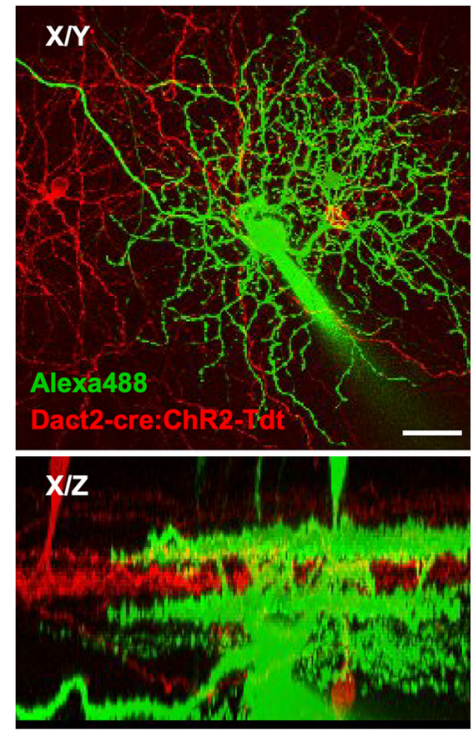

D

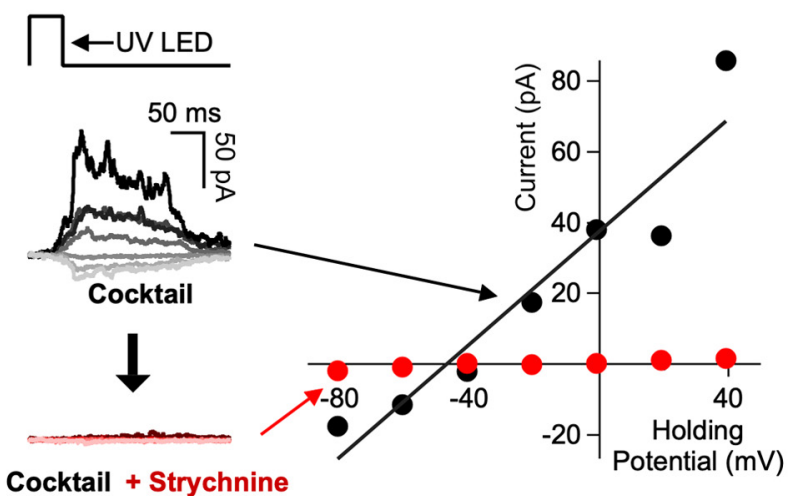

D
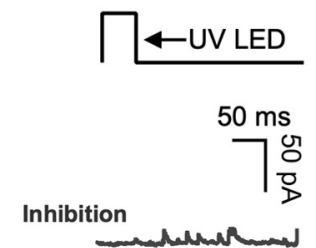

Cocktail

Excitation

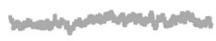

Figure 10. ChR2-evoked glycine release from the MAC. To test for glycinergic output from MACs, RGCs were randomly targeted in the Dact2-Cre:ChR2-Tdt line. Inhibitory input from ChR2expressing cells was isolated with a pharmacological cocktail that blocks visual responses and glutamatergic synaptic transmission. A UV light step was then used to probe for positive connections, and Alexa-488 was included in the recording solution and imaged after recording to aid in RGC identification. $\boldsymbol{A}$, Example of a small arbor monostratified RGC (Alexa-488, green) with one ChR2-Tdt(red)-labeled MAC within its dendritic arbor. $\boldsymbol{B}$, ChR2-evoked responses recorded from the RGC in $\boldsymbol{A}$ for a range of holding potentials (i.e., -80 to $40 \mathrm{mV}$ ). The amplitudes of the responses are plotted as a function of holding potential in the initial cocktail (gray traces), and in the presence of $1 \mu \mathrm{m}$ strychnine (red traces). C, D, Example recording of an ON-0FF direction selective RGC in response to ChR2 activation in the Dact2-Cre:ChR2-Tdt line. C, Projections of an Alexa-488-filled bistratified 00DS RGC in the Dact2-Cre:ChR2-Tdt line. D, Voltage-clamp recordings of excitatory and inhibitory synaptic currents from the 00DS RGC in C during ChR2 activation.

from ON CBCs, ON amacrine cells, or from Müller glia (Figs. 4 and 5).

Which cells provide excitatory synaptic input to MACs? Our SBFSEM reconstructions revealed both conventional (Figs. 3A4, $7 A 1$ ) and ribbon-type synaptic input to MACs (Fig. 7B2). This observation, along with a lack of light-evoked inhibitory inputs (Fig. 6), led us to hypothesize that MACs receive glutamatergic input from bipolar cells and possibly a glutamatergic amacrine cell. Recent studies have described an amacrine cell that expresses VGlut3 (Haverkamp and Wassle, 2004; Johnson et al., 2004; Grimes et al., 2011) and releases glutamate (Lee et al., 2014, 2016; T. Kim et al., 2015). Overlapping stratification in the central layers of the IPL suggests that VGlut3 ACs could provide input to MACs (Fig. 2D). We tested for these connections using both anatomic and physiological approaches. First, we crossed the Plcxd2-GFP line with a mouse line that expresses YFP tagged to the glutamate receptor scaffold PSD95 and labeled these retinas with the VGlut3 antibody. Despite the substantial overlap in stratification, PSD95 was rarely observed at appositions between VGlut3 ACs and MACs (an average of three examples per MAC, $n=2)$. This suggests that VGlut3 ACs provide, at most, a minor input to MACs. Second, paired recordings $(n=6)$ between overlapping MACs and VGlut3 ACs (in a Plcxd2-GFPxVGlut3-creTdt mouse line) failed to show obvious signal transmission between these two amacrine cell types (data not shown).

Closer inspection the 5 MACs identified in our SBFSEM datasets revealed that the conventional synaptic inputs to MACs come exclusively from narrowly stratified wide-field amacrine cells (17 \pm 5 synapses per MAC) whose processes tended to extend entirely through the SBFSEM volumes (Fig. $7 A, G$ ). According to our reconstructions, a majority of the wide-field amacrine processes receive ribbon-type synaptic input from Type 5t (ON) CBCs (Fig. 7G). One might predict that these wide-field amacrines would therefore provide GABAergic input to MACs in response to light increments, but we found no evidence for light-evoked inhibition in our dark-adapted MAC recordings (Fig. $6 D-G$ ), nor did we observe robust hyperpolarizing responses to varying spot sizes at higher light levels (Fig. 6A$C)$. The characteristics and signaling roles of the synaptic connections with these wide-field amacrine cells remains a topic for 
A
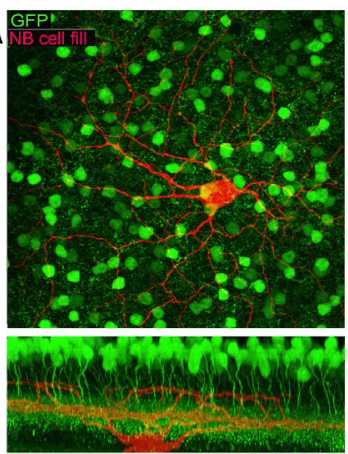

C
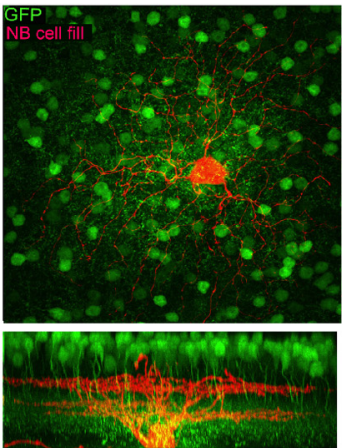
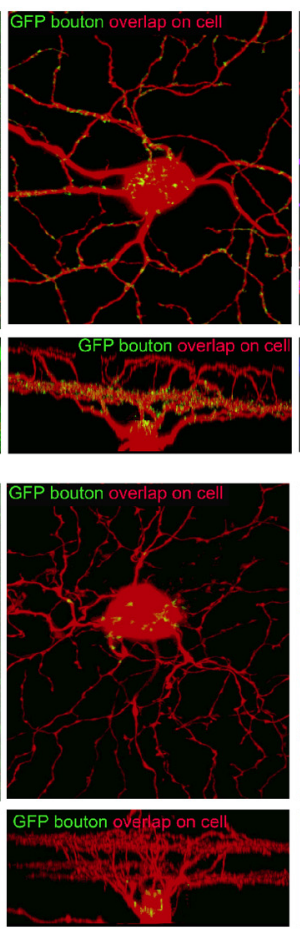
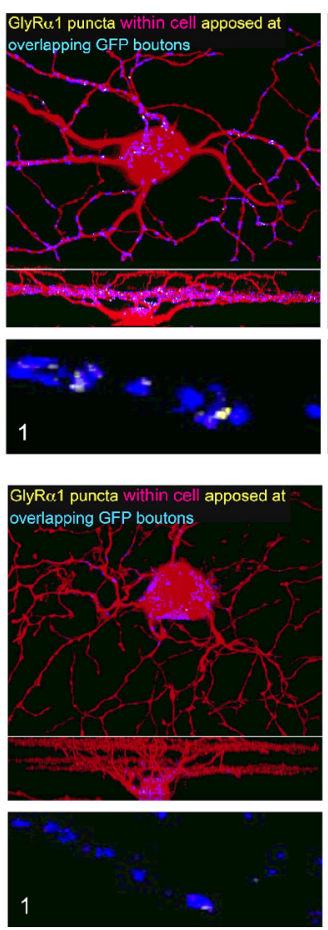

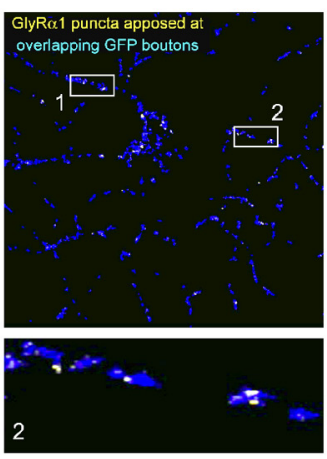

B
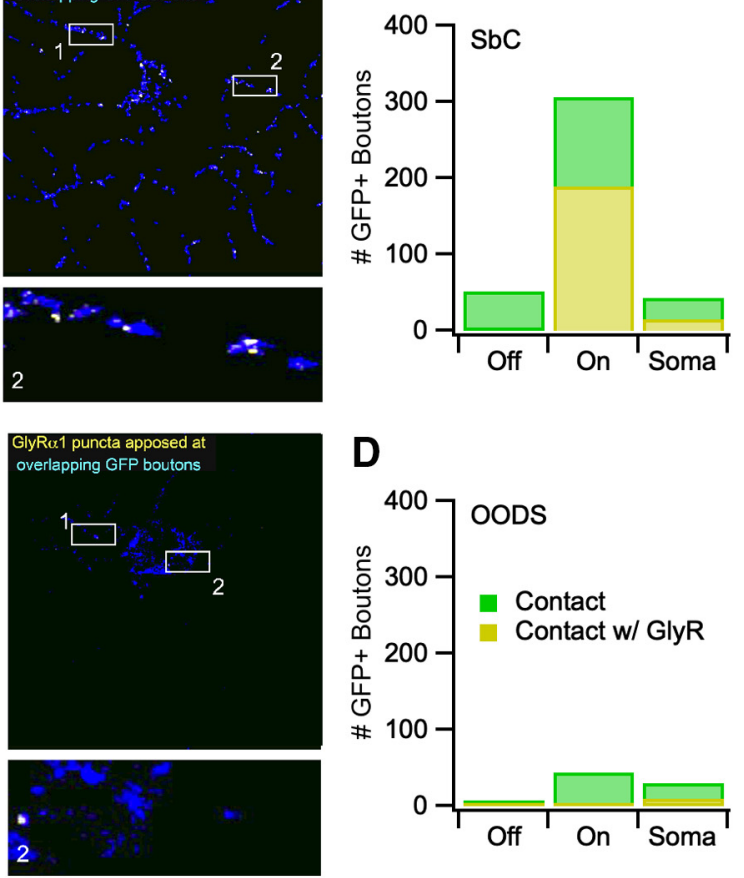

D

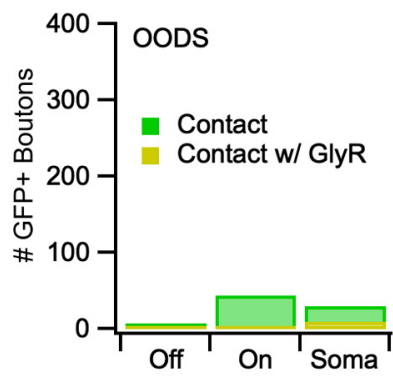

Figure 11. IHC identification of glycine receptors at putative contacts between MACs and RGCs in the Plcxd2-GFP line. RGCs were randomly injected with neurobiotin, before chemical fixation. GlyR $\alpha 1$ antibody and fluorescently tagged streptavidin were used to label glycinergic synapses and neurobiotin-loaded RGCs, respectively. Overlap between neurobiotin and GFP signals was ascertained in $3 \mathrm{D}$, together with the GlyR $\alpha 1$ signals within the RGC processes. $\boldsymbol{A}$, Example showing glycinergic contacts with a bistratified ganglion cell with morphology similar to that described for the suppressed-by-contrast RGC (Tien et al., 2015; Lee et al., 2016). B, Quantification of the total number of GFP boutons (green) that overlap with the neurobiotin-labeled RGCS broken down by RGC compartment (i.e., dendrites in the OFF and ON layers of the IPL, and RGC soma). Yellow bars represent the fraction of these contacts that were apposed to GlyR puncta within the RGC. C, Example of an ON-OFF direction-selective ganglion cell with the same colabeling protocol. D, Bar graph showing low overlap of the 00DS with Plcxd2-GFP boutons (green), and a lack of GlyR $\alpha 1$ at most overlapping terminals (yellow).

future studies. MACs in the K0725 block received excitatory inputs from bipolar cells previously identified as Type 5o and Type 6 CBCs (Ding et al., 2016; Graydon et al., 2018) (Fig. 7E-G; see Materials and Methods).

MACs likely make conventional glycinergic output synapses Across all reconstructed MACs $(n=5)$, we found $53 \pm 12$ conventional chemical output synapses onto amacrine, bipolar, and RGCs (Fig. 3E). We used IHC and optogenetics to determine the molecular identity of the neurotransmitter released at these conventional synapses.

Previous anatomic studies have correlated amacrine arbor size with neurotransmitter phenotype: narrow-field amacrine cells are typically glycinergic, whereas wider-field amacrine cells are GABAergic (Pourcho and Goebel, 1983; Menger et al., 1998). To determine whether narrow-field MACs contain elevated levels of glycine, we performed IHC on retinal slices from the Dact2-GFP line (Fig. 8A,B), and compared the glycine immunoreactivity within $\mathrm{GFP}^{+} \mathrm{MAC}$ somas to measurements taken from locations throughout the INL and ONL within the same slices (see Materials and Methods; Fig. 8C). The INL contains a mixture of bipolar, amacrine, and horizontal cells and represents a very diverse set of neurons with various levels of expected glycine immunoreactivity (e.g., some ON CBCs express glycine because of their gap junctions with glycinergic amacrine cells) (Vaney et al., 1998). As expected, we observed a broad distribution of glycine expression across 50 somatic ROIs (Fig. $8 \mathrm{C}$, purple bars). The ONL, on the other hand, contains somas of photoreceptors that do not express glycine. We therefore compared immunoreactivity in the $\mathrm{GFP}^{+}$somas (green bars) to the distribution of immunoreactivity for 50 equivalent measurements taken from the ONL of the same slice (Fig. $8 \mathrm{C}$, black bars). Glycine immunoreactivity in $\mathrm{GFP}^{+}$somas fell well outside the distribution of ONL glycine expression in the same slices (Fig. $8 C$ ), indicating the MACs do express significant levels of glycine $\left(p=7 \times 10^{-7}\right.$ for 6 Dact2-GFP ${ }^{+}$cells vs 300 ONL control measurements, Wilcoxon Rank test). We also examined glycine immunoreactivity in retinal slices taken from the Plcxd2-GFP line (Fig. 8D-I). For these experiments, a second glycine antibody (rat) was also used. Measurements from the ONL showed that the rat-derived glycine antibody exhibited less background noise than the rabbit antibody, but both antibodies labeled $\mathrm{GFP}^{+}$ somas significantly (rabbit: $p=2 \times 10^{-6}$ for 6 Plcxd2-GFP $P^{+}$cells vs 50 ONL control measurements, Wilcoxon Rank test, Fig. $8 F$; rat: $p=22 \times 10^{-10}$ for 6 Plcxd2-GFP ${ }^{+}$cells vs 50 ONL control measurements, Wilcoxon Rank test, Fig. 8I).

Dact2-GFP retinas (whole mount) were tested for immunoreactivity to molecular machinery commonly associated with inhibitory amacrine cells (e.g., GlyT1, GAD67). The GlyT1 antibody failed to produce clear labeling of Dact2-GFP ${ }^{+}$cells $(0$ of 8 Dact2-GFP ${ }^{+}$cells; $n=3$ animals), and similar results were found

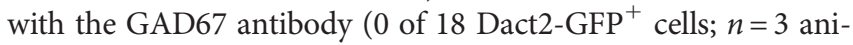
mals; Fig. 9A,B). This result is consistent with transcriptome sequencing data for PPP1R17-expressing amacrines (Macosko et al., 2015), but a subsequent publication from the same group indicated that low expression of GlyT1 mRNA is reliably present in these cells (Yan et al., 2020). In light of their results, we used FISH to see whether MACs indeed express low levels of GlyT1 mRNA. FISH is more sensitive than conventional IHC measurements, and did reveal significant, albeit low, levels of GlyT1 mRNA expression in MACs $(p=0.0007$ for 3 Dact2-GFP 

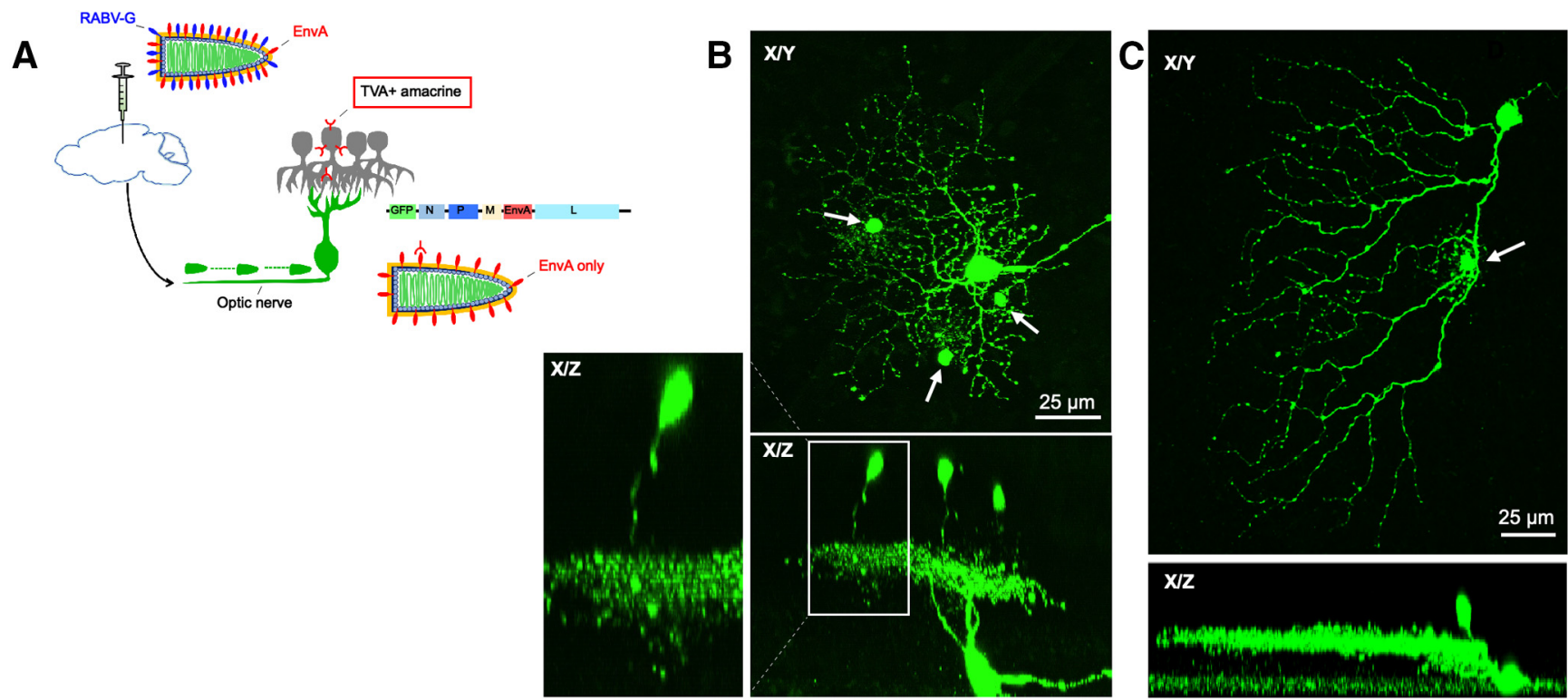

PPP1R17
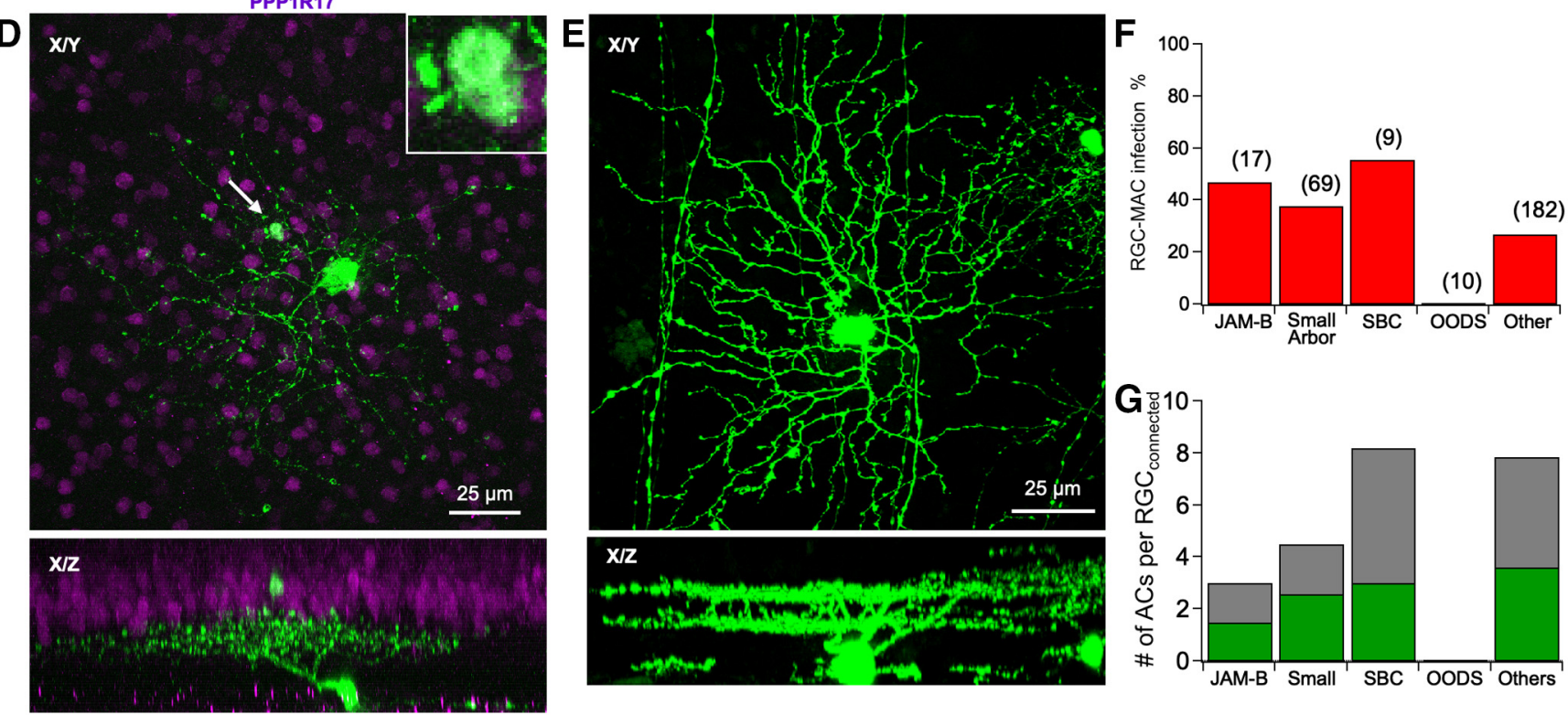

Figure 12. Assessment of MAC- $>$ RGC connectivity using viral tracing. A, A version of VSV that can infect virtually any cell type was injected into the LGN of mice. This form of VSV has the RABV-G protein on its surface and can be taken up by axonal terminals and can travel retrogradely to a cell body. In the cell body, the virus can replicate and spread from an initially infected RGC. However, as the viral genome only encodes the EnvA/RABV-G glycoprotein, the virus can only transmit to cells expressing the TVA receptor. TVA expression was driven in these mice following cre-dependent recombination of a TVA allele in NEX-Cre mice, hence leading to TVA expression in a subset of MACs. Many RGCs were infected by these injections, but a large number of these RGCs did not transmit to any amacrine cell nearby. RGCS with GFP-expressing amacrine cells within their dendritic arbors indicate a potential synaptic connection between the two cell types and were identified as connected RGCS. B-E, Views of infected RGCs with connected MACs (identified by morphology or PPP1R17 antibody labeling; see Materials and Methods). $\boldsymbol{B}$, Example of a putative W3 RGC with multiple ACs labeled by the virus (arrows). Note the costratification seen in the X-Z plane, and the remarkable similarity to the connected RGC shown in Figure 10A. C, Example of a Jamb RGC (arrow) with one virally labeled AC. D, Example of an infected AC-RGC pair ("unknown" RGC) with PPP1R17 antibody labeling. Inset, High-magnification view of the virally infected amacrine cell body labeled by PPP1R17. E, Example of a virally infected, but unconnected, OODS RGC (i.e., no virally labeled amacrine cells). $\boldsymbol{F}$, Graph quantifying the percentage of infected RGCs with virally labeled MACs (number of observations for each cell type in parentheses). G, Quantification of the number of coupled amacrine cells per "connected" RGC. Gray represents all connected amacrine cells. Green represents identified MACs (through morphology or PPP1R17 labeling; see Materials and Methods).

cells vs 150 ONL control measurements, Wilcoxon Rank test; Fig. 9C).

Together with the pattern of chemical output synapses we observed in our SBFSEM reconstructions (Fig. 3E), these data suggest that MACs may release glycine onto multiple cell types in the IPL, including RGCs. To test for functional glycine release, we made recordings from RGCs in a mouse line that expresses ChR2 in a sparse subset of MACs (Dact2-cre/Tdt-ChR2). Unlike the Dact2-GFP line, which exclusively and sparsely labeled MACs, the Dact2-cre/Tdt-ChR2 retinas also expressed tdTomato-tagged
ChR2 in wide-field (presumably GABAergic) amacrines and RGCs. The wider repertoire of labeling with Tdt-ChR2 in the Dact2-cre line likely reflects the sensitivity and history of the activity of the Cre allele at this locus, but another cross (i.e., Dact2-cre x YFP-tagged ChR2) failed to label MACs entirely. We made whole-cell recordings from a random collection of RGCs in a flat-mount retinal preparation (Fig. 10), and used a cocktail of APB, NBQX, APV, and UBP to block glutamatergic synaptic transmission throughout the retina while leaving direct inhibitory synaptic transmission intact (Lee et al., 2014, 2016; Park et al., 2015; Tien et al., 2016). A spot of 

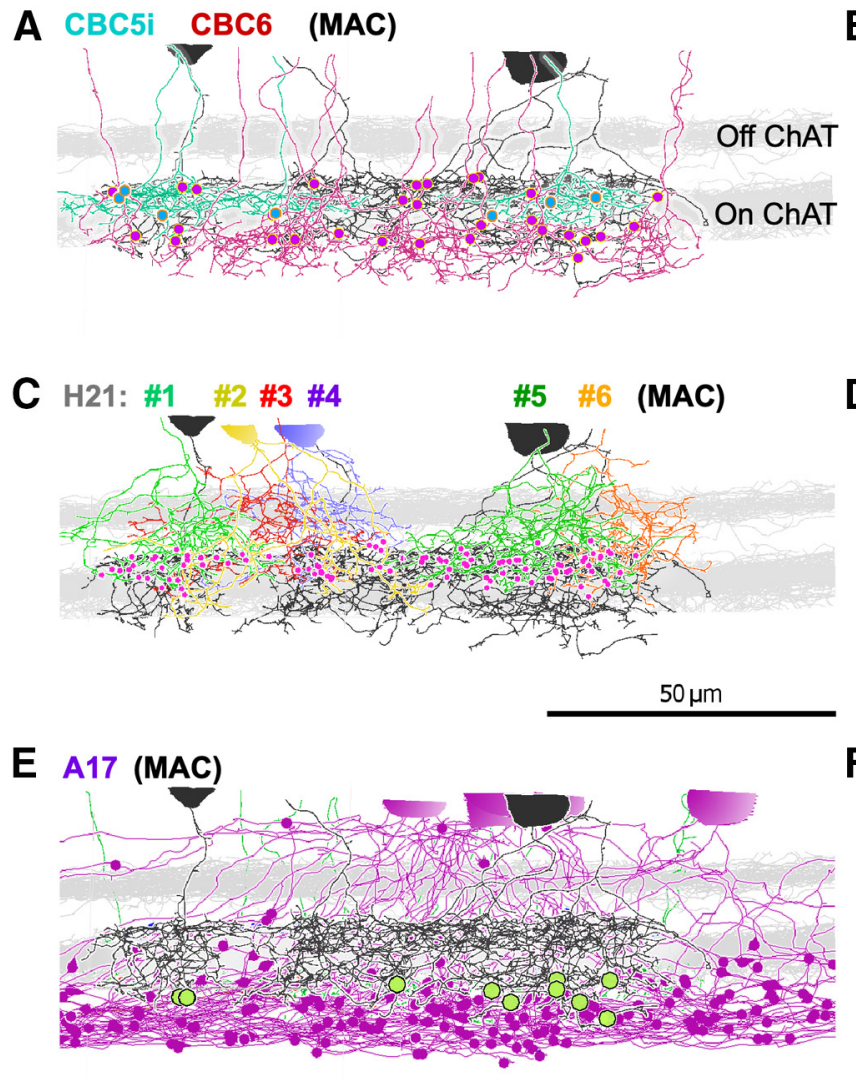

\section{G}

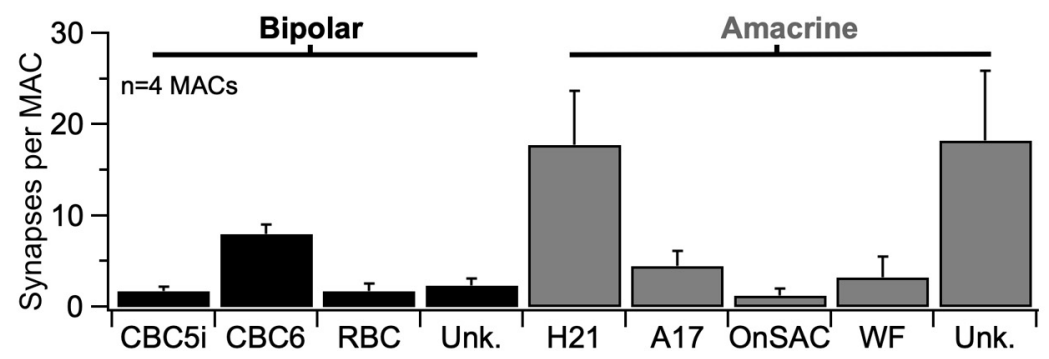

Figure 13. Serial block face EM reconstructions of postsynaptic targets of the MAC. A, MACs make chemical synapses onto $\mathrm{CBC} 5 \mathrm{i}$ and $\mathrm{CBC6}$. Colored dots represent synapses. $\boldsymbol{B}$, Electron micrograph of an identified synapse between the MAC and $\mathrm{CBC}$. C, MACs synapse onto a narrow-field amacrine type we identify as Type 21 from Helmstaedter et al. (2013) (H21). D, Electron micrograph of an identified synapse between the MAC and H21. E, MACs make synapses onto A17 neurites in sublamina 4 of the IPL. Green dots represent synapses from the 4 reconstructed MACs onto A17s. Magenta dots represent ribbon input to the A17. $\boldsymbol{F}$, Electron micrograph of an identified synapse between an MAC and A17. G, Average number of identified output synapses per reconstructed MAC $(n=4)$, broken down by postsynaptic cell type. Inconsistent postsynaptic partners (i.e., $<1$ synapse per MAC on average) are excluded from this graph but are included in the analysis in $\boldsymbol{E}$.

UV light was then delivered to the retina to test for ChR2-driven responses in RGCs. Of 48 RGCs tested, only one showed a robust $\mathrm{ChR} 2$-evoked response. Synaptic currents recorded from this RGC (Fig. 10A,B) reversed near the expected reversal potential for a $\mathrm{Cl}^{-}$mediated $\left(\mathrm{E}_{\mathrm{Cl}}\right)$ conductance and were completely blocked by the glycine receptor antagonist, strychnine (1 $\mu \mathrm{M} ;$ Fig. 10B). Subsequent imaging of the RGC and the ChR2- $\mathrm{Tdt}^{+}$cells revealed a single MAC within the proximal arbor of a narrowly stratified small arbor RGC with morphology similar to one of the W3 RGC types (i. e., Local Edge Detector; Fig. 10A) (Helmstaedter et al., 2013). Other RGCs, like the ON-OFF direction-selective (OODS) cell $(n=9)$, failed to respond to ChR2 activation (Fig. 10C, $D$ ). The low success rate of these experiments likely reflects a combination of several features: sparse MAC labeling in the

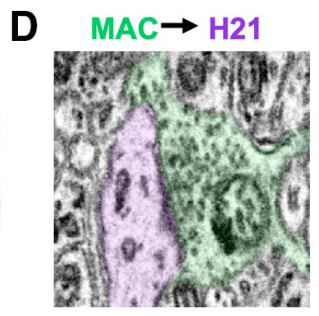

Dact2-cre/Tdt-ChR2 retina (most RGCs we tested had 0-1 MACs within their entire dendritic arbor), a low number of RGC contacts per MAC (Fig. 3E), and a high degree of specificity in MAC connectivity with RGCs. The low success rate left us unable to establish RGC type-specific connections with any certainty. Nonetheless, this experimental approach provided an example of an MAC providing functional glycinergic output onto an RGC.

We also tested for glycine receptors at contacts between randomly labeled RGCs and MACs using IHC (see Materials and Methods). Retinas with labeled RGCs were fixed and stained with antibodies against the $\alpha 1$ subunit of the glycine receptor (GlyR $\alpha 1$ ) (Wassle et al., 1998) and neurobiotin when relevant (Fig. 11). This approach revealed substantial overlap between $\mathrm{GFP}^{+}$amacrine arbors and the dendrites of a presumed suppressed-by-contrast (SbC) RGC (Jacoby et al., 2015; Tien et al., 2015, 2016; Lee et al., 2016; Jacoby and Schwartz, 2018). We then determined the number of overlapping $\mathrm{GFP}^{+}$boutons that were apposed to GlyR $\alpha 1$ puncta. GlyR $\alpha 1$-expressing boutons accounted for approximately twothirds of the $\mathrm{GFP}^{+}$presynaptic boutons found in the SbC's ON dendrites (Fig. $11 A, B)$. By comparison, an exemplary ON-OFF Direction-Selective RGC showed very little contact with $\mathrm{GFP}^{+}$ boutons (even in the ON layer); and of those that did, less than half were located across from a GlyR $\alpha 1$ puncta (Fig. 11C,D). Together, these data argue that, although MACs do not highly express GlyT1 (Fig. 9), they are likely to release glycine at conventional chemical synapses onto RGCs (Figs. 10,11) and possibly other neurons in the IPL (i.e., bipolar and amacrine cells, Fig. 3E).

\section{MACs provide outputs to bipolars, amacrines, and RGCs in a highly selective manner}

We used a viral tracing technique to more broadly assess MAC connectivity with RGCs (Fig. 12). For this purpose, we used a mouse line with Cre expression in a more substantial number of MACs (NEX-Cre) (Kay et al., 2011). This line also drives Cre expression in other amacrine cell types; thus, visual identification of the MAC's unique morphology and/ or the PPP1R17 antibody (Fig. 2) was used to determine whether the connected amacrine cells were indeed MACs (see Materials and Methods). We used a variant of VSV that encodes within its genome the ectodomain of the avian EnvA glycoprotein fused to the cytoplasmic domain of the rabies virus glycoprotein (RABV$\mathrm{G})$, hereafter referred to as the $\mathrm{A} / \mathrm{G}$ protein (Beier et al., 2013). The NEX-Cre mouse was used to specify the expression of TVA, either by crossing to a floxed-TVA mouse (Seidler et 
al., 2008; Beier et al., 2013) or by introduction of a flexed-TVA-mCherry construct (Miyamichi et al., 2013). VSV was pseudotyped with the rabies virus glycoprotein (RABV-G) to allow the injected virus to be taken up by any cell at the inoculation site. VSV-A/G pseudotyped with RABV-G was injected into a retinorecipient brain area (the lateral geniculate nucleus), where it was taken up by RGC axon terminals (Fig. $12 A)$. Retrogradely transported virus replicates once it is in the cell body of a RGC, and then spreads transynaptically from the RGC to amacrine cells that express TVA. This method allowed us to probe many RGC types for connectivity to MACs. Subsequent confocal imaging of these retinas showed that RGCs connected to MACs were enriched for several RGC types with distinct, known morphologies (Fig. $12 B-F$ ) as follows: (1) RGCs with small arbors (e.g., HD1, HD2 and W3; Fig. 12B) (Jacoby and Schwartz, 2017; T. Kim and Kerschensteiner, 2017); (2) RGCs with highly asymmetric dendrites (e.g., JamB, F-mini; Fig. 12C) (I. J. Kim et al., 2008; Rousso et al., 2016); and (3) RGCs that are asymmetrically bistratified (e.g., SbC) (Jacoby et al., 2015; Tien et al., 2015). Some RGCs with virally connected MACs were not easily identified based on morphology, and were thus lumped into the "unknown" category (Fig. 12D). RGCs with virally connected MACs sometimes had multiple amacrine cells labeled within their arbors (Fig. 12G). Because of the heterogeneity of the NEX-Cre line, there were a few virally infected RGCs that had only non-MAC ACs connections; these RGCs were excluded from the final analysis and cell counts. Notably, the exemplary cell for the small arbor RGC in Figure $12 B$ is (to us) morphologically indistinguishable from the RGC showing the robust connectivity via ChR2 strategy in Figure 10A, further supporting this connectivity pattern. Although many different RGC types were labeled with this approach, all encountered OODS RGCs $(n=10)$, a well-known RGC type that costratifies with the MAC, lacked trans-synaptically labeled MACs (Fig. 12E,F). This lack of apparent connectivity between MACs and OODS RGCs is further supported by our IHC experiments, which showed a lack of colocalization between NB-injected OODS RGCs, GlyR $\alpha 1$ puncta, and GFP-labeled amacrine cells in the Plcxd2-GFP line (Fig. $11 C)$. Previous work has confirmed that this approach effectively identifies synaptic partners of OODS cells and exhibits limited false-positives (Beier, et al., 2013). Together, the data in Figures 8, 10-12 argue that MACs provide feedforward inhibition onto specific RGC types by way of conventional glycinergic synaptic transmission, while avoiding others (e.g., OODS).

Our initial SBFSEM results indicated that the majority of MAC output synapses are made onto bipolar and amacrine cells (Fig. $3 E$ ), but our circuit-tracing techniques were impractical for broad assessment of MAC connectivity with the other $\sim 60$ cell types residing in the INL. In lieu of this, we returned to the large SBFSEM dataset (Ding et al., 2016) and partially reconstructed all neurons postsynaptic to the MACs. From these reconstructions, we confirmed the identity of two amacrine cell types and one bipolar cell type that consistently received direct chemical synaptic output from the MACs. Each MAC $(n=4)$ makes an average of 8 output synapses onto Type 6 CBCs (Fig. $13 A, B, G)$. This result, combined with the finding that MACs receive substantial input from Type 6 CBCs (Fig. 7E-G), suggests a feedback inhibition role. In support of this notion, we also found multiple examples of direct reciprocal connectivity between each MAC/type $6 \mathrm{CBC}$ pair. MACs receive substantial input from Type 5 CBCs (in particular Type 5o), but these CBCs are only a minor output target of the MAC. MACs also made chemical synapses onto a narrow-field amacrine cells that we identified as Type 21 (18 synapses per MAC) in Helmstaedter et al. (2013) (Fig. 13C,D). MACs also synapsed onto A17 amacrine cell dendrites in sublamina 4 (5 synapses per MAC; Fig. 13E-G), a well-known amacrine that participates in visual processing under dim lighting conditions. This suggests that MACs might also play a role in visual processing at night, when mice are most active.

\section{Discussion}

Here we present our initial findings regarding the physiology and synaptic connectivity of the MAC (Fig. 14), the second-most numerous amacrine cell type in the mouse retina. The results indicate, unexpectedly, that MACs are directly coupled to Müller glia. Direct coupling between neurons and glia is unusual (see Alvarez-Maubecin et al., 2000; Pakhotin and Verkhratsky, 2005) and has not previously been reported in the mammalian retina, but few studies have tested this possibility directly. We speculate that MACs might play an important role in retinal functions involving neuron-glia interactions. For example, recent work (Biesecker et al., 2016) has revealed neuron-glia interactions in the IPL that lead to vasodilation of retinal capillaries (within the INL) in response to increased neural activity, although the identity of the neuron(s) participating in this functional hyperemia remain unclear. Biesecker et al. (2016) found that this neurovascular coupling pathway involves $\mathrm{IP}_{3}$-dependent calcium release 
within the Müller glia, which could, in theory, be triggered by gap junction transmission of $\mathrm{IP}_{3}$ signals generated in the MAC (Boitano et al., 1992). Another possibility is that $\mathrm{Ca}^{2+}$ signals generated in the MAC are transmitted through gap junctions to Müller glia, where they could then trigger intracellular signaling pathways, either directly or by boosting ER calcium stores, previously shown to enhance $\mathrm{IP}_{3} \mathrm{R}$ sensitivity to $\mathrm{IP}_{3}$ (Missiaen et al., 1992).

Another interesting feature of the MAC is their poor expression of traditional GABAergic and glycinergic markers (e.g., GAD67 and GlyT1) that label most amacrine types in a mutually exclusive manner. This observation is consistent with published transcriptomic data on PPP1R17 ${ }^{+}$ACs (Macosko et al., 2015) and suggests that MACs are members of a recently characterized amacrine subpopulation originally termed non-GABAergic, nonglycinergic (nGnG) amacrine cells (Kay et al., 2011). Our data indicate, however, that these cells do release glycine via conventional synaptic transmission. We also note that our ISH did reveal low levels of GlyT1 within these cells (Fig. 9C) and that this observation is consistent with a recent publication examining gene expression across amacrine types (in which the MAC seemingly corresponds to cluster \#30) (Yan et al., 2020). Some apparent non-GABAergic, nonglycinergic amacrine cells may therefore release glycine despite low levels of expression of the commonly associated synaptic and transporter genes/proteins. It remains unclear how MACs acquire the appropriate levels of glycine, but glycine can pass through gap junctions (Vaney et al., 1998; Deans et al., 2002), and Müller glia, which we show are gap junctionally coupled to MACs, take up extracellular glycine using GlyT1 in culture (Hosoya et al., 2010).

Our data also indicate that MACs receive light-evoked glutamatergic input but provided little evidence for inhibition in response to the visual stimuli used in our experiments (Fig. 6). This physiological result is surprising given that, according to our EM reconstructions, the majority of input synapses to the MAC come from wide-field amacrine cells (Figs. $3 E$ and $7 A, G$ ). One possibility is that these presynaptic amacrine cells release glutamate onto the MAC. Recent work has shown that one amacrine cell type expresses VGlut3 and releases glutamate (Lee et al., 2014, 2016), which led us to test for possible connections with the MAC. However, both paired physiology recordings and immunohistochemical analysis failed to show substantial connectivity between MACs and VGlut3 amacrine cells. A recent publication on sequencing data of the amacrine population has revealed an amacrine cell type that expresses VGluT1, but an initial screening suggests that the VGLUT1 ${ }^{+}$amacrine cell arbors are confined to sublamina 1 of the IPL (Yan et al., 2020). Since our serial EM reconstructions of the MAC $(n=5)$ showed no evidence for synaptic connections in sublaminas 1 and 2 (Figs. 3 and 7), synaptic inputs from the VGLUT1 ${ }^{+}$amacrine cell seems unlikely. Other possibilities are that we have not yet found a visual stimulus that drives these presynaptic wide-field amacrines effectively, or that these interneurons provide tonic, but not phasic, inhibition to the MAC.

The cell type-specific connections with the MAC (Figs. 7, 12, and 13) suggest enticing targets for future physiology studies. For example, our reconstructions indicate that MACs make reciprocal connections with Type 6 CBCs. Type 6 CBCs provide the majority of feedforward excitation to the ON $\alpha$ RGC (Schwartz et al., 2012), a known intrinsically photosensitive RGC (M4) (Estevez et al., 2012; Schroeder et al., 2018) with dynamic receptive fields (Farrow et al., 2013; Grimes et al., 2014). We were also intrigued by the MAC's synaptic outputs to A17 amacrine cells. These synaptic contacts were restricted to sublaminas 4 and 5 of the IPL, where A17 amacrine cells make reciprocal GABAergic synapses with rod bipolar cells (Nelson and Kolb, 1985; Hartveit, 1999; Grimes et al., 2010). Serial inhibition of this nature could disinhibit the rod bipolar cell axon terminal when the MAC is active and thereby influence signaling near visual threshold.

In conclusion, the results and approaches presented here raise intriguing questions regarding potential roles for MACs in visual processing and neurovascular coupling and suggest a number of powerful tools (transgenic mouse lines, antibody labels, circuittracing) to address those questions in future studies.

\section{References}

Ahrens JP, Geveci B, Law CC (2005) ParaView: an end-user tool for largedata visualization. Elsevier.

Alvarez-Maubecin V, Garcia-Hernandez F, Williams JT, Van Bockstaele EJ (2000) Functional coupling between neurons and glia. J Neurosci 20:4091-4098.

Beier KT, Borghuis BG, El-Danaf RN, Huberman AD, Demb JB, Cepko CL (2013) Transsynaptic tracing with vesicular stomatitis virus reveals novel retinal circuitry. J Neurosci 33:35-51.

Biesecker KR, Srienc AI, Shimoda AM, Agarwal A, Bergles DE, Kofuji P, Newman EA (2016) Glial cell calcium signaling mediates capillary regulation of blood flow in the retina. J Neurosci 36:9435-9445.

Bishop D, Nikic I, Brinkoetter M, Knecht S, Potz S, Kerschensteiner M, Misgeld T (2011) Near-infrared branding efficiently correlates light and electron microscopy. Nat Methods 8:568-570.

Boitano S, Dirksen ER, Sanderson MJ (1992) Intercellular propagation of calcium waves mediated by inositol trisphosphate. Science 258:292-295.

Bunt-Milam AH, Saari JC (1983) Immunocytochemical localization of two retinoid-binding proteins in vertebrate retina. J Cell Biol 97:703-712.

Deans MR, Volgyi B, Goodenough DA, Bloomfield SA, Paul DL (2002) Connexin36 is essential for transmission of rod-mediated visual signals in the mammalian retina. Neuron 36:703-712.

Della Santina L, Kuo SP, Yoshimatsu T, Okawa H, Suzuki SC, Hoon M, Tsuboyama K, Rieke F, Wong RO (2016) Glutamatergic monopolar interneurons provide a novel pathway of excitation in the mouse retina. Curr Biol 26:2070-2077.

Ding H, Smith RG, Poleg-Polsky A, Diamond JS, Briggman KL (2016) Species-specific wiring for direction selectivity in the mammalian retina. Nature 535:105-110.

Dingledine R, Borges K, Bowie D, Traynelis SF (1999) The glutamate receptor ion channels. Pharmacol Rev 51:7-61.

Drokhlyansky E, Göz Aytürk D, Soh TK, Chrenek R, O’Loughlin E, Madore C, Butovsky O, Cepko CL (2017) The brain parenchyma has a type I interferon response that can limit virus spread. Proc Natl Acad Sci USA 114:E95-E104.

Estevez ME, Fogerson PM, Ilardi MC, Borghuis BG, Chan E, Weng S, Auferkorte ON, Demb JB, Berson DM (2012) Form and function of the M4 cell, an intrinsically photosensitive retinal ganglion cell type contributing to geniculocortical vision. J Neurosci 32:13608-13620.

Farrow K, Teixeira M, Szikra T, Viney TJ, Balint K, Yonehara K, Roska B (2013) Ambient illumination toggles a neuronal circuit switch in the retina and visual perception at cone threshold. Neuron 78:325-338.

Goebbels S, Bormuth I, Bode U, Hermanson O, Schwab MH, Nave KA (2006) Genetic targeting of principal neurons in neocortex and hippocampus of NEX-Cre mice. Genesis 44:611-621.

Govardovskii VI, Fyhrquist N, Reuter T, Kuzmin DG, Donner K (2000) In search of the visual pigment template. Vis Neurosci 17:509-528.

Graydon CW, Lieberman EE, Rho N, Briggman KL, Singer JH, Diamond JS (2018) Synaptic transfer between rod and cone pathways mediated by AII amacrine cells in the mouse retina. Curr Biol 28:2739-2751.e3.

Grimes WN, Zhang J, Graydon CW, Kachar B, Diamond JS (2010) Retinal parallel processors: more than 100 independent microcircuits operate within a single interneuron. Neuron 65:873-885.

Grimes WN, Seal RP, Oesch N, Edwards RH, Diamond JS (2011) Genetic targeting and physiological features of VGLUT3 $^{+}$amacrine cells. Vis Neurosci 28:381-392. 
Grimes WN, Schwartz GW, Rieke F (2014) The synaptic and circuit mechanisms underlying a change in spatial encoding in the retina. Neuron 82:460-473.

Hartveit E (1999) Reciprocal synaptic interactions between rod bipolar cells and amacrine cells in the rat retina. J Neurophysiol 81:2923-2936.

Haverkamp S, Wassle H (2004) Characterization of an amacrine cell type of the mammalian retina immunoreactive for vesicular glutamate transporter 3. J Comp Neurol 468:251-263.

Helmstaedter M, Briggman KL, Turaga SC, Jain V, Seung HS, Denk W (2013) Connectomic reconstruction of the inner plexiform layer in the mouse retina. Nature 500:168-174.

Hosoya K, Ichikawa T, Akanuma S, Hirose S, Tachikawa M (2010) Glycine and L-arginine transport in cultured Muller glial cells (TR-MUL). Neurochem Int 57:262-268.

Jacoby J, Schwartz GW (2017) Three small-receptive-field ganglion cells in the mouse retina are distinctly tuned to size, speed, and object motion. J Neurosci 37:610-625.

Jacoby J, Schwartz GW (2018) Typology and circuitry of suppressed-by-contrast retinal ganglion cells. Front Cell Neurosci 12:269.

Jacoby J, Zhu Y, Devries SH, Schwartz GW (2015) An amacrine cell circuit for signaling steady illumination in the retina. Cell Rep 13:2663-2670.

Johnson J, Sherry DM, Liu X, Fremeau RT Jr, Seal RP, Edwards RH, Copenhagen DR (2004) Vesicular glutamate transporter 3 expression identifies glutamatergic amacrine cells in the rodent retina. J Comp Neurol 477:386-398.

Jorstad NL, Wilken MS, Grimes WN, Wohl SG, Vandenbosch LS, Yoshimatsu T, Wong RO, Rieke F, Reh TA (2017) Stimulation of functional neuronal regeneration from Muller glia in adult mice. Nature 548:103-107.

Kay JN, Voinescu PE, Chu MW, Sanes JR (2011) Neurod6 expression defines new retinal amacrine cell subtypes and regulates their fate. Nat Neurosci 14:965-972.

Ke JB, Wang YV, Borghuis BG, Cembrowski MS, Riecke H, Kath WL, Demb JB, Singer JH (2014) Adaptation to background light enables contrast coding at rod bipolar cell synapses. Neuron 81:388-401.

Kim IJ, Zhang Y, Yamagata M, Meister M, Sanes JR (2008) Molecular identification of a retinal cell type that responds to upward motion. Nature 452:478-482.

Kim T, Kerschensteiner D (2017) Inhibitory control of feature selectivity in an object motion sensitive circuit of the retina. Cell Rep 19:1343-1350.

Kim T, Soto F, Kerschensteiner D (2015) An excitatory amacrine cell detects object motion and provides feature-selective input to ganglion cells in the mouse retina. Elife 4:e08025.

Kolb H (1995) Neurotransmitters in the retina. In: Webvision: the organization of the retina and visual system (Kolb H, Fernandez E, Nelson R, eds.) Salt Lake City: Moran Eye Center.

Lee S, Chen L, Chen M, Ye M, Seal RP, Zhou ZJ (2014) An unconventional glutamatergic circuit in the retina formed by vGluT3 amacrine cells. Neuron 84:708-715.

Lee S, Zhang Y, Chen M, Zhou ZJ (2016) Segregated glycine-glutamate cotransmission from vGluT3 amacrine cells to contrast-suppressed and contrast-enhanced retinal circuits. Neuron 90:27-34.

Macosko EZ, Basu A, Satija R, Nemesh J, Shekhar K, Goldman M, Tirosh I, Bialas AR, Kamitaki N, Martersteck EM, Trombetta JJ, Weitz DA, Sanes JR, Shalek AK, Regev A, McCarroll SA (2015) Highly parallel genomewide expression profiling of individual cells using nanoliter droplets. Cell 161:1202-1214.

Manookin MB, Weick M, Stafford BK, Demb JB (2010) NMDA receptor contributions to visual contrast coding. Neuron 67:280-293.

Masland RH (2012) The tasks of amacrine cells. Vis Neurosci 29:3-9.

Matsuda T, Cepko CL (2007) Controlled expression of transgenes introduced by in vivo electroporation. Proc Natl Acad Sci USA 104:1027-1032.

Menger N, Pow DV, Wassle H (1998) Glycinergic amacrine cells of the rat retina. J Comp Neurol 401:34-46.

Mills SL, Massey SC (1995) Differential properties of two gap junctional pathways made by AII amacrine cells. Nature 377:734-737.

Missiaen L, De Smedt H, Droogmans G, Casteels R (1992) $\mathrm{Ca}^{2+}$ release induced by inositol 1,4,5-trisphosphate is a steady-state phenomenon controlled by luminal $\mathrm{Ca}^{2+}$ in permeabilized cells. Nature 357:599-602.
Miyamichi K, Shlomai-Fuchs Y, Shu M, Weissbourd BC, Luo L, Mizrahi A (2013) Dissecting local circuits: parvalbumin interneurons underlie broad feedback control of olfactory bulb output. Neuron 80:12321245

Morgan JL, Schubert T, Wong RO (2008) Developmental patterning of glutamatergic synapses onto retinal ganglion cells. Neural Dev 3:8.

Murphy GJ, Rieke F (2011) Electrical synaptic input to ganglion cells underlies differences in the output and absolute sensitivity of parallel retinal circuits. J Neurosci 31:12218-12228.

Nelson R, Kolb H (1985) A17: a broad-field amacrine cell in the rod system of the cat retina. J Neurophysiol 54:592-614.

Pakhotin P, Verkhratsky A (2005) Electrical synapses between Bergmann glial cells and Purkinje neurones in rat cerebellar slices. Mol Cell Neurosci 28:79-84.

Pallotto M, Watkins PV, Fubara B, Singer JH, Briggman KL (2015) Extracellular space preservation aids the connectomic analysis of neural circuits. Elife 4:e08206.

Pang JJ, Gao F, Wu SM (2010) Light responses and morphology of bNOSimmunoreactive neurons in the mouse retina. J Comp Neurol 518:24562474 .

Pang JJ, Gao F, Wu SM (2012) Physiological characterization and functional heterogeneity of narrow-field mammalian amacrine cells. J Physiol 590:223-234.

Pang JJ, Paul DL, Wu SM (2013) Survey on amacrine cells coupling to retrograde-identified ganglion cells in the mouse retina. Invest Ophthalmol Vis Sci 54:5151-5162.

Park SJ, Borghuis BG, Rahmani P, Zeng Q, Kim IJ, Demb JB (2015) Function and circuitry of $\mathrm{VIP}^{+}$interneurons in the mouse retina. J Neurosci 35:10685-10700.

Polyak AL (1941) The retina. Chicago: University of Chicago.

Pourcho RG, Goebel DJ (1983) Neuronal subpopulations in cat retina which accumulate the GABA agonist, $(3 \mathrm{H})$ muscimol: a combined Golgi and autoradiographic study. J Comp Neurol 219:25-35.

Rousso DL, Qiao M, Kagan RD, Yamagata M, Palmiter RD, Sanes JR (2016) Two pairs of ON and OFF retinal ganglion cells are defined by intersectional patterns of transcription factor expression. Cell Rep 15:1930-1944.

Schroeder MM, Harrison KR, Jaeckel ER, Berger HN, Zhao X, Flannery MP, St Pierre EC, Pateqi N, Jachimska A, Chervenak AP, Wong KY (2018) The roles of rods, cones, and melanopsin in photoresponses of M4 intrinsically photosensitive retinal ganglion cells (ipRGCs) and optokinetic visual behavior. Front Cell Neurosci 12:203.

Schwartz GW, Okawa H, Dunn FA, Morgan JL, Kerschensteiner D, Wong RO, Rieke F (2012) The spatial structure of a nonlinear receptive field. Nat Neurosci 15:1572-1580.

Seidler B, Schmidt A, Mayr U, Nakhai H, Schmid RM, Schneider G, Saur D (2008) A Cre-loxP-based mouse model for conditional somatic gene expression and knockdown in vivo by using avian retroviral vectors. Proc Natl Acad Sci USA 105:10137-10142.

Shekhar K, Lapan SW, Whitney IE, Tran NM, Macosko EZ, Kowalczyk M, Adiconis X, Levin JZ, Nemesh J, Goldman M, McCarroll SA, Cepko CL, Regev A, Sanes JR (2016) Comprehensive classification of retinal bipolar neurons by single-cell transcriptomics. Cell 166:1308-1323.e30

Sigulinsky CL, Anderson JR, Kerzner E, Rapp CN, Pfeiffer RL, Rodman TM, Emrich DP, Rapp KD, Nelson NT, Lauritzen JS, Meyer M, Marc RE, Jones BW (2020) Network architecture of gap junctional coupling among parallel processing channels in the mammalian retina. J Neurosci 40:4483-4511.

Sun W, Li N, He S (2002) Large-scale morphological survey of mouse retinal ganglion cells. J Comp Neurol 451:115-126.

Tien NW, Pearson JT, Heller CR, Demas J, Kerschensteiner D (2015) Genetically identified suppressed-by-contrast retinal ganglion cells reliably signal self-generated visual stimuli. J Neurosci 35:1081510820.

Tien NW, Kim T, Kerschensteiner D (2016) Target-specific glycinergic transmission from VGluT3-expressing amacrine cells shapes suppressive contrast responses in the retina. Cell Rep 15:1369-1375. 
Trexler EB, Li W, Massey SC (2005) Simultaneous contribution of two rod pathways to AII amacrine and cone bipolar cell light responses. J Neurophysiol 93:1476-1485.

Trexler EB, Li W, Mills SL, Massey SC (2001) Coupling from AII amacrine cells to ON cone bipolar cells is bidirectional. J Comp Neurol 437:408-422.

Tsukamoto Y, Omi N (2017) Classification of mouse retinal bipolar cells: type-specific connectivity with special reference to rod-driven AII amacrine pathways. Front Neuroanat 11:92.

Vaney DI, Nelson JC, Pow DV (1998) Neurotransmitter coupling through gap junctions in the retina. J Neurosci 18:10594-10602.

Voinescu PE, Emanuela P, Kay JN, Sanes JR (2009) Birthdays of retinal amacrine cell subtypes are systematically related to their molecular identity and soma position. J Comp Neurol 517:737-750.
Volgyi B, Chheda S, Bloomfield SA (2009) Tracer coupling patterns of the ganglion cell subtypes in the mouse retina. J Comp Neurol 512:664-687

Wassle H, Koulen P, Brandstatter JH, Fletcher EL, Becker CM (1998) Glycine and GABA receptors in the mammalian retina. Vision Res 38:1411-1430.

Wu SM, Maple BR (1998) Amino acid neurotransmitters in the retina: a functional overview. Vision Res 38:1371-1384.

Xiong W, MacColl Garfinkel AE, Li Y, Benowitz LI, Cepko CL (2015) NRF2 promotes neuronal survival in neurodegeneration and acute nerve damage. J Clin Invest 125:1433-1445.

Yan W, Laboulaye MA, Tran NM, Whitney IE, Benhar I, Sanes JR (2020) Mouse retinal cell atlas: molecular identification of over sixty amacrine cell types. J Neurosci 40:5177-5195. 